\title{
Modulation of Spontaneous Transmitter Release during Depression and Posttetanic Potentiation of Aplysia Sensory-Motor Neuron Synapses Isolated in Culture
}

\author{
Lise S. Eliot, Eric R. Kandel, and Robert D. Hawkins \\ Center for Neurobiology and Behavior, College of Physicians and Surgeons of Columbia University, New York, New York \\ 10032
}

\begin{abstract}
An Aplysia motor neuron cocultured with a single presynaptic sensory neuron exhibits spontaneous miniature EPSPs or EPSCs ("minis") that can be used to assay the release process directly, independent of the presynaptic action potential. Sensory-motor synapses in culture undergo homosynaptic depression with low frequency stimulation $(<1 \mathrm{~Hz}$ ) and posttetanic potentiation (PTP) with high-frequency stimulation $(20 \mathrm{~Hz})$ much as they do in intact ganglia, except that PTP does not occur in culture when sensory neurons are impaled. We measured spontaneous release during each of these two forms of homosynaptic plasticity as a way of testing whether they involve depletion or mobilization of synaptic vesicles (Gingrich and Byrne, 1985). We find that PTP is accompanied by an increase in mini frequency that decays with a time course parallel to the decay of evoked EPSP facilitation. In contrast, depression is not paralleled by a reduction of mini frequency, although extensive stimulation reduces mini frequency for a brief period immediately following stimulation. Neither form of plasticity altered miniature EPSP or miniature EPSC amplitude, corroborating previous evidence that both are presynaptically mediated. These findings suggest that PTP is mediated by a presynaptic mechanism independent of the action potential, such as vesicle mobilization. This presumably $\mathrm{Ca}^{2+}$-dependent mechanism does not involve protein kinase $C$, since we found that the inhibitor $\mathrm{H7}$ does not specifically block PTP. In contrast to PTP, depression appears to involve changes unique to excitation-secretion coupling, such as reduced $\mathrm{Ca}^{2+}$ influx during the action potential (Klein et al., 1980).
\end{abstract}

[Key words: synaptic plasticity, homosynaptic, presynaptic, spontaneous release, evoked release, vesicle depletion]

The simplest and most universal forms of synaptic plasticity are homosynaptic: frequency-dependent depression and facilitation. Individual synapses tend either to decrease or increase

\footnotetext{
Received Feb. 26. 1993; revised Oct. 28, 1993; accepted Nov. 17, 1993.

We thank Sarah Mack and Charles Lam for preparing the figures, Jurek Karle for help with computer programming, and Jack Byrne for comments on the manuscript. This work was supported by the Howard Hughes Medical Institute (F.R.K.) by Grant MH 26212 from the NIMH (R.D.H.), and by an NSF predoctoral fellowship (L.S.E.).

Correspondence should be addressed to Lise Eliot, Division of Neuroscience Baylor College of Medicine, One Baylor Plaza, Houston, TX 77030

Copyright (C) 1994 Society for Neuroscience $0270-6474 / 94 / 143280-13 \$ 05.00 / 0$
}

in strength when repeatedly activated. However, both forms of homosynaptic plasticity can be revealed at most synapses using appropriate manipulations, suggesting that their underlying mechanisms are inherent to the machinery of synaptic transmission (Zucker, 1989).

Early work by Del Castillo and Katz (1954) established that both depression and facilitation are due to presynaptic changes in transmitter release. The most enduring form of short-term homosynaptic enhancement, posttetanic potentiation (PTP), has similarly been shown to be presynaptically mediated at both central and peripheral synapses (Liley, 1956; Hirst et al., 1981; Clamann et al., 1989; Griffith, 1990). In principle, presynaptic mechanisms of short-term plasticity can be divided into two classes: those involving changes in the action potential or $\mathrm{Ca}^{2+}$ influx, and those independent of changes in the action potential, such as changes in vesicle distribution or direct modulation of the release apparatus. Homosynaptic plasticity is generally thought to involve changes of the second class, based in part on findings at the squid giant synapse that neither depression nor facilitation can be accounted for by changes in action potential shape (Takeuchi and Takeuchi, 1962; Charlton and Bittner, 1978), presynaptic $\mathrm{Ca}^{2+}$ current (Charlton et al., 1982), or in the amount of $\mathrm{Ca}^{2+}$ that enters the terminal with each action potential (Miledi and Parker, 1981; Charlton et al., 1982).

The synapses made by Aplysia mechanosensory neurons onto motor neurons and interneurons exhibit both homosynaptic depression and potentiation, but these sensory neurons are unusual in the dramatic extent to which depression is their dominant form of plasticity. Sensory neuron synapses depress at every interval of stimulation, from tens of milliseconds to tens of minutes (Castellucci et al., 1970; Byrne, 1982). At shorter intervals ( $<100 \mathrm{msec}$ ). synapses may facilitate during the first two or three stimuli, but then depress throughout the remainder of the train (Walters and Byrne, 1984). Following a train of stimuli at 6-25 Hz, the synapses display PTP lasting a few minutes (Clark and Kandel 1984; Walters and Byrne, 1984).

Aplysia sensory neuron synapses are advantageous for assessing the functional significance of short-term homosynaptic plasticity. The sensory neurons are the first afferent relay in both the mono- and polysynaptic components of the gill and siphon withdrawal reflex (Koester and Kandel, 1977; Byrme et al., 1978). With repeated activation, the synaptic potential and the reflex depress comparably in magnitude and time course, suggesting that homosynaptic depression in sensory neurons contributes to behavioral habituation (Castellucci et al., 1970). Although 
the behavioral relevance of PTP is less well understood, homosynaptic facilitation would be expected to contribute to two forms of learning that involve brief, high-frequency sensory neuron activity: classical conditioning (Hawkins et al., 1983; Walters and Byrne, 1983) and site-specific sensitization (Walters and Byrne, 1985; Walters, 1987).

Of the two forms of homosynaptic plasticity, depression has been more extensively studied at sensory neuron synapses. Quantal analysis of sensory neuron depression under conditions of low release indicated that it is mediated presynaptically (Castellucci and Kandel, 1974). In contrast to depression in the squid giant synapse, Klein et al. (1980) found that depression during repeated voltage-clamp depolarizing steps is paralleled by a progressive decline in sensory neuron $\mathrm{Ca}^{2+}$ current, suggesting that it is due to a decrease in $\mathrm{Ca}^{3+}$ influx with successive depolarizations. Subsequently, Gingrich and Byrne (1985) modeled the sensory neuron synapse using the published $\mathrm{Ca}^{2+}$ current inactivation parameters and concluded that the inactivation is insufficient to account for the magnitude of synaptic depression observed with repeated action potentials. The authors posited a depletion mechanism to account for the bulk of synaptic depression. In their model, vesicles reside in two pools, a releasable pool and a backup or storage pool. The former is depleted by activity and then slowly replenished by $\mathrm{a} \mathrm{Ca}^{2+}$-dependent mechanism. This model accounts for various parametric features of depression (Byrne, 1982) and even predicted the occurrence of PTP. However, the model may underestimate the contribution of presynaptic $\mathrm{Ca}^{2+}$ current inactivation to depression, because sensory neurons were recently found to have two different types of $\mathrm{Ca}^{2+}$ channels, only one of which, a dihydropyridine-insensitivc channcl, contributes to normal synaptic transmission in sensory neurons (Edmonds et al., 1990). Since Klein et al. (1980) measured inactivation of total $\mathrm{Ca}^{2+}$ current, it remains possible that the component contributing to release undergoes greater inactivation than the total current.

To analyze further the mechanisms of short-term homosynaptic plasticity in Aplysia sensory neurons, we studied the phenomenon in culture. Both depression and PTP have been shown to persist in isolated cultures containing single Aplysia sensory and motor neurons, confirming that each form of plasticity is intrinsic to the synapse, and does not require additional circuit elements (Rayport and Schacher, 1986; Schacher et al., 1990). The ability to reconstitute the synapse between single adult sensory and motor neurons in culture provides a number of other advantages for mechanistic analysis. In particular, we have exploited the ability to measure miniature excitatory postsynaptic responscs (mEPSPs or mEPSCs, "minis") that unambiguously reflect transmitter release from a single presynaptic neuron. Measurements of mini amplitude allow a direct assay for changes in quantal amplitude, while measurements of mini frequency provide an assay for modulatory mechanisms that are independent of the action potential, such as vesicle mobilization and depletion.

\section{Materials and Methods}

Cell culture. The methods for reconstituting synapses between single Aplysia sensory and motor neurons have been previously described (Rayport and Schacher, 1986; Schacher et al., 1990; Eliot et al., 1994). Synapses between abdominal or pleural sensory neurons and motor neurons L 7 or LFS were reestablished in polylysine-coated plastic dishes in a solution containing $50 \%$ sterile filtered Aplysia hemolymph and $50 \%$ L15 medium (Flow Laboratories, supplemented to the following final concentrations: $385 \mathrm{~mm} \mathrm{NaCl}, 10 \mathrm{~mm} \mathrm{KCl}, 11 \mathrm{~mm} \mathrm{CaCl}, 28 \mathrm{~mm}$
$\mathrm{MgCl}_{2}, 27 \mathrm{~mm} \mathrm{MgSO}{ }_{4}, 2.3 \mathrm{~mm} \mathrm{NaHCO}, 35 \mathrm{~mm}$ D-glucose, $50 \mathrm{U} / \mathrm{ml}$ streptomycin, $50 \mu \mathrm{g} / \mathrm{ml}$ penicillin). Synaptic connections appeared as early as $24 \mathrm{hr}$ after plating and growth at room temperature. Dishes were transferred to an $18^{\circ} \mathrm{C}$ incubator after $24 \mathrm{hr}$. Experiments were performed $1-4 \mathrm{~d}$ after plating.

Electrophysiology. All recording was performed at room temperature in mcdium containing 50\% supplemented L 15 and 50\% artificial seawater ( $460 \mathrm{~mm} \mathrm{NaCl}, 10 \mathrm{~mm} \mathrm{KCl}, 55 \mathrm{mM} \mathrm{MgCl}_{2}, 11 \mathrm{~mm} \mathrm{CaCl}, 2 \mathrm{~mm}$ $\mathrm{NaHCO}_{3}, 10 \mathrm{~mm}$ Na-HEPES, pH 7.6). Sensory neurons were either stimulated intracellularly, using $20-30 \mathrm{M} \Omega$ microelectrodes (filled with a solution of $2 \mathrm{M} \mathrm{K}$-acetate, $0.5 \mathrm{M} \mathrm{KCl}, 10 \mathrm{~mm}$ K-HEPES, pH 7.2) or extracellularly, using an unpolished patch pipette $(1-3 \mathrm{M} \Omega)$ filled with recording medium and coated with silver paint to allow concentric, bipolar stimulation. Extracellular stimulus strength was adjusted by gradually increasing the intensity of a $0.1 \mathrm{msec}$ voltage pulse until a single EPSP was observed in the motor neuron. For most experiments, the synapse was tested once with a single presynaptic action potential and then rested $15 \mathrm{~min}$ before beginning the experiment. Motor neurons were held hyperpolarized (to -80 to $-90 \mathrm{mV}$ ) to measure evoked EPSPs. All recording was performed using an Axoclamp $2 \mathrm{~A}$ amplifier. Current-clamp mcasurcments were performed in bridge mode, while mEPSCs were recorded in continuous single electrode voltage-clamp mode.

Measurements of spontaneous release. Spontaneous transmitter release was measured exclusively in cultures containing a single sensory neuron in contact with a single motor neuron, and was assessed in two ways. Initially, we recorded mEPSPs in L7 motor neuron synapses (2$3 \mathrm{~d}$ postplating), while in later experiments we recorded mEPSCs in synapses onto LFS motor neurons ( $1-2 \mathrm{~d}$ postplating). L7 is quite large $(300-400 \mu \mathrm{m})$ and thus can be impaled with a low-resistance sharp microelectrode (6-8 M $\Omega$ beveled and filled with $1.25 \mathrm{M} \mathrm{K}$-acetate, 1.25 $\mathrm{M} \mathrm{KCl}, 10 \mathrm{~mm} \mathrm{~K}$-HEPES, pH 7.2). The frequency of detectable minis is higher in the smaller $(50-100 \mu \mathrm{m})$ LFS cells, probably because their input resistance is 3-10 times higher than L7s. The disadvantage of LFS followers is that they tend to have large oscillations in their membranc potential which are reduced, but not eliminated by holding the cell hyperpolarized. These oscillations made it difficult to accurately detect mEPSPs in most cultures. However, the oscillations disappeared when the cells were voltage clamped and internally dialyzed with $\mathrm{Cs}^{+}$-containing solutions. To record mEPSCs, LFS motor neurons were held at $-50 \mathrm{mV}$ under whole-cell voltage clamp with fire-polished patch pipettes (3-4 M 2 ) filled with $465 \mathrm{~mm}$ Cs-gluconate, $2 \mathrm{mM} \mathrm{MgCl}_{2}, 1 \mathrm{~mm}$ $\mathrm{CaCl}_{2}, 10$ mм K-EGTA, $5 \mathrm{~mm} \mathrm{Na}$,ATP, $0.1 \mathrm{~mm}$ Tris-GTP, $10 \mathrm{~mm}$ reduced glutathione, and $50 \mathrm{~mm}$ Cs-HEPES, buffered to pH 7.2 with $\mathrm{CsOH}$.

Analyses of mEPSP and mEPSC ("mini") frequencies and amplitudes were performed as previously described (Dale and Kandel, 1990; Eliot et al., 1994). Briefly, high-gain recordings (AC coupled) were filtered ( $300 \mathrm{~Hz}$ for mEPSPs, and $2-4 \mathrm{kHz}$ for mEPSCs), digitized $(4 \mathrm{kHz}$ sampling frequency) and measured using a PDP- 11 computer and programs written in BASIC-23. The starting point of each mini was detected manually based on rapid rise time and amplitude greater than the peakto-peak noise level (approximately $40 \mu \mathrm{V}$ in current-clamp recordings and $6 \mathrm{pA}$ in voltage-clamp recordings; see Figs. $5 B, 11 \mathrm{~B}$ ) and then the peak amplitude and the interval between minis were determined automatically. Distributions of mini amplitudes generally yielded multiple peaks, with the majority of events in the lowest amplitude class. Largeramplitude events tended to be integral multiples of the smallest mean amplitude, particularly in the case of mEPSP distributions. Unitary mini amplitude is taken as the mean of the first peak of amplitude histograms fit with one to three Gaussian distributions using the simplex algorithm and the method of maximum likelihood (Dale and Kandel, 1990). Avcrage unitary mEPSP amplitude was $99.4 \pm 12.0$ (SEM) $\mu \mathrm{V}(n-11)$. Average unitary mEPSC amplitude was $20.7 \pm 3.0 \mathrm{pA}(n=13)$. Experiments were rejected if the noise level increased during the experiment to the point of exceeding the smallest signals detectable at the beginning of the experiment.

Data analysis. Group data are presented throughout as mean \pm SEM, normalized to initial or pretetanus level. In experiments measuring spontaneous release, both mini frequencies and evoked EPSP amplitudes were $\log$ transformed and then normalized for both statistical analysis and graphical display, where the data are plotted as geometric mean \pm SEM (see Figs. $6,9,10 \mathrm{~A}, 12$ ). Because spontaneous release frequency is quite low, it was necessary to sample it over long intervals. To compare evoked and spontaneous release we thus compared average mini frequency during an interval to the average amplitude of two 
A

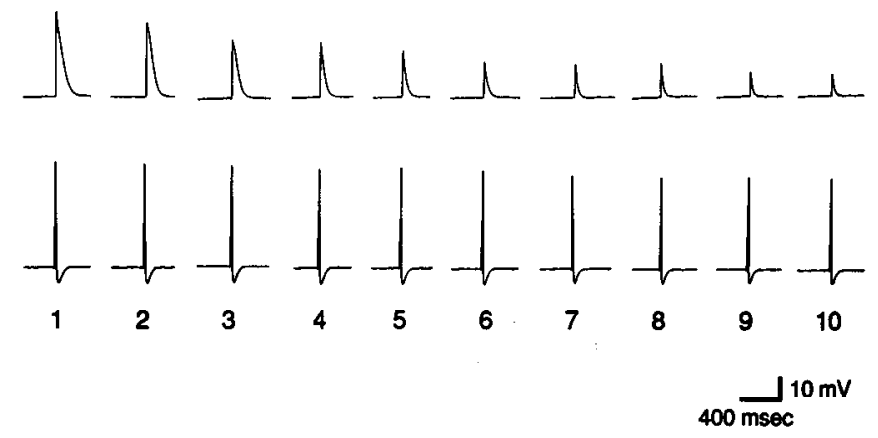

B

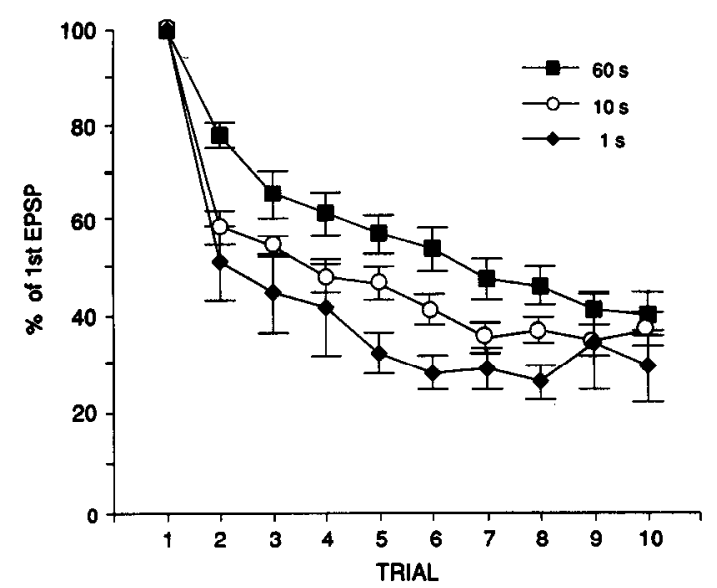

Figure 1. Homosynaptic depression in culture. A, Depression in a sensory-LFS motor neuron synapse stimulated intracellularly at $60 \mathrm{sec}$ intervals. $B$, Shorter stimulus intervals produce greater depression. In this data set, depression at a $60 \mathrm{sec}$ intcrval $(n=13)$ is significantly different from both the $10 \mathrm{sec}$ interval $(n=8)$ the $1 \mathrm{sec}$ interval $(n=$ $6)$, but the $10 \mathrm{sec}$ and $1 \mathrm{sec}$ intervals are not significantly different from each other ( $p<0.05$, by Student-Newman-Keuls' test). Each experiment was performed on a naive synapse.

evoked EPSPs tested at either end of the interval. This procedure is preferable to comparing a single EPSP measurement to average mini frequency in two bracketing intervals because it allows some averaging to correct for variability in evoked release.

Within-group comparisons to pretest measures were evaluated using one-way ANOVA with repeated measures followed by Dunnett's multiple range test. Between-group comparisons were evaluated using twoway ANOVA with repeated measures (with time and treatment as factors) followed by Student-Newman-Keuls' test for comparing multiple groups, or $t$ tests for comparing two groups at individual time points.

\section{Results}

Homosynaptic depression and potentiation occur in culture but are altered by sensory neuron impalement

As was found previously for cultures containing single sensory and L7 motor neurons (Rayport and Schacher, 1986; Schacher et al., 1990), sensory-to-LFS motor neuron synapses show both homosynaptic depression and facilitation in culture. Figure $1 \mathrm{~A}$ illustrates depression of the EPSP to repeated intracellular stimulation of the sensory neuron at $60 \mathrm{sec}$ intervals. Depression occurred at every stimulus interval tested, from $50 \mathrm{msec}$ to 10 min. Average depression resulting from stimulating different synapses at 1,10 , or $60 \mathrm{sec}$ intervals is plotted in Figure $1 B$. Depression kinetics in culture are very similar to the ganglion (Byrne, 1982), with about half of the total decrease occurring between the first and second stimuli, and shorter stimulus intervals producing a greater amount of depression. This is reflected as a significant overall effect of stimulus interval on the magnitude of depression $\left(F_{2,24}=7.40, p<0.05\right)$.

In contrast to the depression exhibited during low-frequency stimulation, sensory neuron synapses in culture undergo PTP following a high-frequency $(20 \mathrm{~Hz}, 2 \mathrm{sec})$ tetanus (Fig. $2 B_{1}$ ). Considerable depression occurs during the train, but 1 min later, the synapse is substantially facilitated, and remains enhanced for 5-10 min following the tetanus. Group data from 17 such experiments are shown in Figure $3 A$. Facilitation was significant overall $\left(F_{1,18}=8.11, p<0.02\right)$ and at the $1 \mathrm{~min}(p<0.05)$ and 5 min $(p<0.02)$ linne points, when compared to test-alone controls $(n=3)$. Potentiation also occurs in synapses that are substantially depressed. Thus, the same tetanus largely reverses the depression induced by 10 stimuli delivered at low frequency (Fig. 3B). This is reflected as a significant overall difference between tetanized and control depressed groups $\left(F_{1.9}=6.44, p\right.$ $<0.05)$ and significant differences at all individual posttests at early time points ( $p<0.05$, one-tailed $t$ test), but not at 7,8 , and $10 \mathrm{~min}$ posttetanus.

The most dramatic difference between PTP in culture and in the ganglion is that PTP does not occur when the sensory neuron is impaled and stimulated intracellularly (Fig. $2 B_{2}$ ). Although extracellular stimulation may elicit action potentials in a somewhat different manner from intracellular stimulation, it did not produce PTP in cells that were concurrently impaled by a microelectrode (not shown). It was possible, in some cases, to induce PTP with extracellular stimulation 30 min after removal of an intracellular electrode. A likely explanation for these observations is that impalement elevates intracellular $\mathrm{Ca}^{2+}$, effectively occluding PTP. Two additional observations are consistent with this interpretation. First, synaptic depression was significantly greater when elicited with extracellular stimulation than in sensory neurons that were impaled and stimulated intracellularly $\left(F_{\mathrm{I} .20}=8.86, p<0.01 ;\right.$ Fig. 4$)$. Second, the interval between consecutive mEPSCs was significantly shorter in LFS synapses in which the presynaptic sensory neuron was impaled $(6.8 \pm 2.6 \mathrm{sec}, n=5)$ compared to synapses in which the sensory neuron was not impaled $(14.7 \pm 2.5 \mathrm{sec}, n=8 ; p<0.05$ by one-tailed $t$ test). Both of these observations support the interpretation that impalement elevates intracellular $\mathrm{Ca}^{2+}$, producing a modest level of facilitation that counteracts depression, elevates resting mini frequency, and interferes with PTP.

These results demonstrate that both depression and PTP can be induced in culture, where they display many of the same properties as in the ganglion. We next took advantage of the ability to measure spontaneous transmitter release in culture to gain insight into the mechanisms underlying these two forms of homosynaptic plasticity.

PTP is accompanied by an increase in frequency, but not amplitude, of spontaneous $m E P S P S$

Figure 5 illustrates spontaneous and evoked EPSPs in an L7 synapse before and after tetanization. Resting mEPSP frequency is quite low, especially since the sensory neuron was not impaled in these experiments (mean rate $=1$ mEPSP every $20.9 \pm 1.6$ sec, $n=5$ ). Immediately following tetanization, mEPSP frequency increases dramatically, by about 15 -fold on average. We omitted the $1 \mathrm{~min}$ posttest of evoked release in these experimonts to provide an uninterrupted interval for measuring spontaneous release after the tetanus. Although the initial increase 


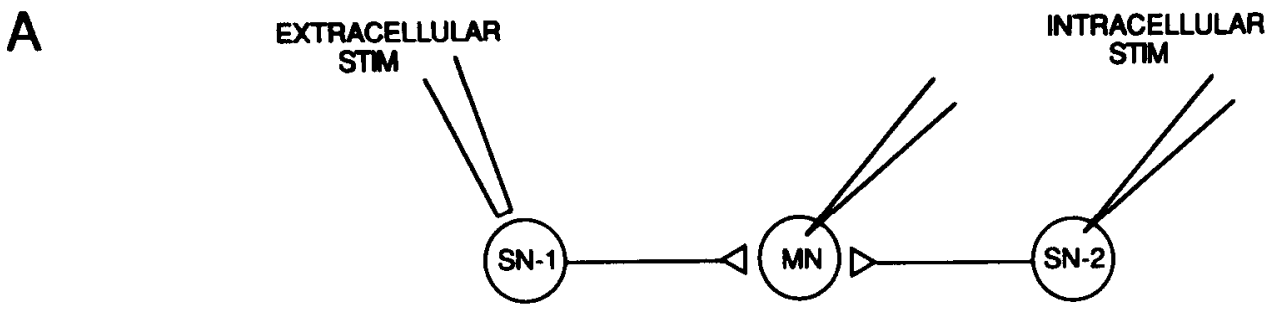

\section{B1 EXTRACELLULAR STIM}

PRE

EPSP-1<smiles>CCCCCCCC</smiles>

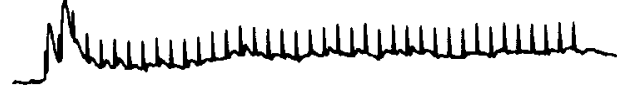

$10 \mathrm{~min}$

TETANUS

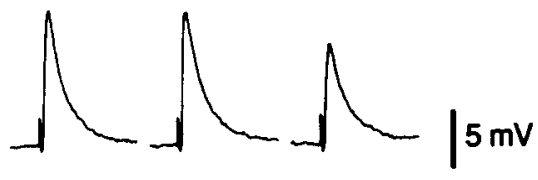

$11 \mathrm{~min} 15 \mathrm{~min} 20 \mathrm{~min}$

\section{B2 INTRACELLULAR STIM}

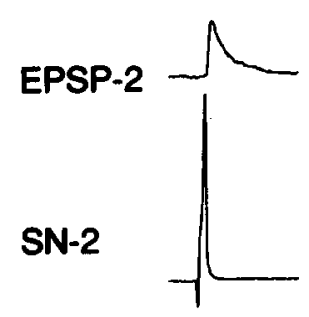

$2.5 \mathrm{~min}$

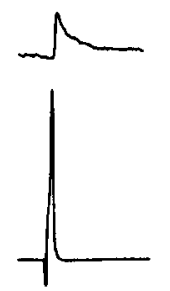

$7.5 \mathrm{~min}$

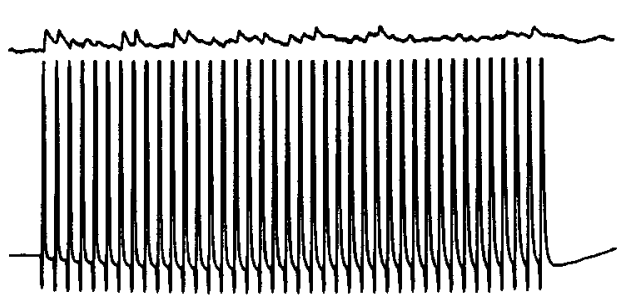

$12.5 \mathrm{~min}$

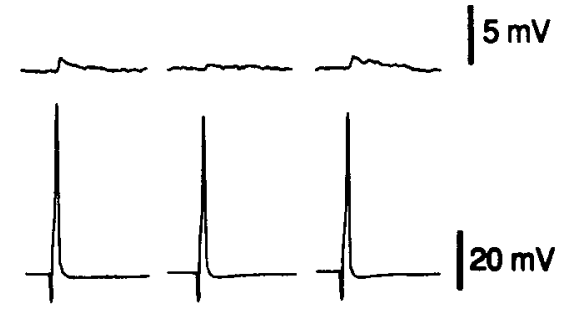

$13.5 \mathrm{~min} 17.5 \mathrm{~min} 22.5 \mathrm{~min}$

\section{$100 \mathrm{msec}$}

Figure 2. PTP can be elicited in culture, but not when the sensory neuron is impaled. $A$, Diagram of experimental design. Two sensory neurons $(S N S)$ synapsing on a common motor neuron were stimulated at 5 min intervals (offset from each other by $2.5 \mathrm{~min}$ ). $S N-2$ was stimulated with an intracellular microelectrode while $S N-I$ was stimulated extracellularly as described in Materials and Methods. $B_{1}$, The EPSP from $S N-1$ shows PTP up to $10 \mathrm{~min}$ after extracellular tetanization $(20 \mathrm{~Hz}$ for $2 \mathrm{sec}) . B_{2}$, In contrast, the EPSP from $S N-2$ shows depression, rather than PTP following the same tetanus delivered intracellularly.

in mini frequency appears greater than the facilitation of evoked release at $1 \mathrm{~min}$ seen in the prcvious sct of experiments (Fig. $3 A$ ), this initial increase decays rapidly, leaving a smaller, though still substantial enhancement of spontaneous release whose decay roughly parallels the decay of PTP of the evoked EPSP (Fig. $6)$. Both the increases in mini frequency and evoked EPSP amplitude were significant overall $\left(F_{5.20}=58.48\right.$ and $F_{3.12}=11.30$ for spontaneous and evoked release, respectively; $p<0.001)$ and at individual time points through 10 min posttetanus $(p<$ 0.01 for both effects, Dunnett's test), but not at later time points. Changes in mEPSP frequency are larger than changes in evoked release, such that a twofold increase in mEPSP frequency in the interval between 5 and 10 min posttetanus corresponds to about $50 \%$ facilitation of the EPSP.

We next analyzed mEPSP amplitudes to look for changes in quantal size during PTP. Figure $7 A$ shows the distribution of mEPSP sizes before and after tetanus in the experiment illustrated in Figure 5. Although the sample sizes were fairly small before tetanus, in four of five experiments it was possible to fit amplitude histograms with gaussian distributions to determine the size of the unitary potential. Unitary mEPSP amplitude did not change after tetanization $(+0.6 \pm 3.3 \%$ of pretetanus amplitude; Fig. $7 B$ ), indicating that changes in quantal size cannot account for facilitation of the evoked EPSP. The fact that PTP of the evoked EPSP is accompanied by an increase in frequency, with no change in amplitude of spontaneous mEPSPs, suggests that it is mediated by a presynaptic mechanism. That the same mechanism underlies the enhancement of both evoked and spontaneous release is further suggested by the fact that intracellular tetanization, which fails to induce PTP, did not produce the dramatic enhancement of spontaneous release seen following extracellular tetanization (not shown).

PTP is not blocked by $H 7$

The enhancement of spontaneous release following tetanization is reminiscent of a similar increase in the presence of 5-HT (Dale and Kandel, 1990). The effect of 5-HT on spontaneous release appears to be mediated, at least in part, by protein kinase 

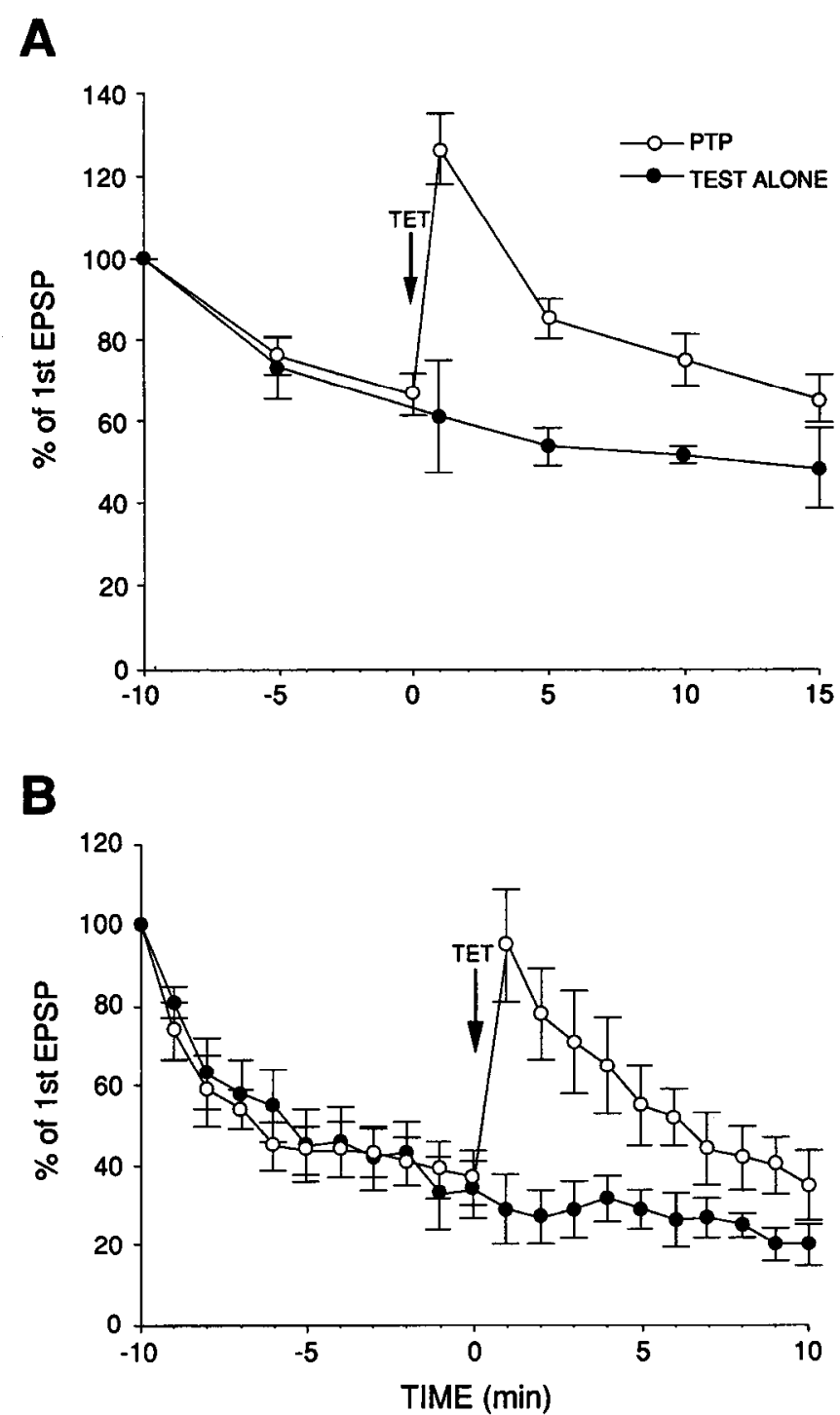

Figure 3. Time course of PTP: group data. $A$, PTP following a tetanus $(20 \mathrm{~Hz} \times 2 \mathrm{sec})$ in mildly depressed synapses $(n=17)$ compared to test alone controls $(n=3)$. B. PTP following homosynaptic depression $(n$ $=7$ ) compared to test alone controls $(n=4)$. The same tetanus reverses the depression produced by 10 stimuli. All experiments were performed using extracellular stimulation of sensory neurons.

$\mathrm{C}$, because it is both mimicked by phorbol esters and blocked by the kinase inhibitor H7 (Ghirardi et al., 1992). Furthermore, 5-HT has been shown to translocate protein kinase $\mathrm{C}$ activity from cytosol to membrane (Sacktor and Schwartz, 1990) and to activate specifically the $\mathrm{Ca}^{2+}$-dependent form of the enzyme in sensory neurons (Sossin and Schwartz, 1992). If the large $\mathrm{Ca}^{2+}$ influx that occurs during a tetanus is by itself capable of activating protein kinase $C$, this activation could contribute to PTP and the enhancement of spontaneous release that accompanies it. Such a mechanism would be consistent with evidence from $\mathrm{Ca}^{2+}$ imaging studies suggesting that posttetanic forms of facilitation are mediated by a $\mathrm{Ca}^{2+}$-dependent process distinct from the release mechanism itself (Delaney et al., 1989; Swandulla et al., 1991). Protein kinase $C$ is a good candidate for playing a role in PTP based on its $\mathrm{Ca}^{2+}$ dependence and the fact that it enhances both spontaneous and evoked release from

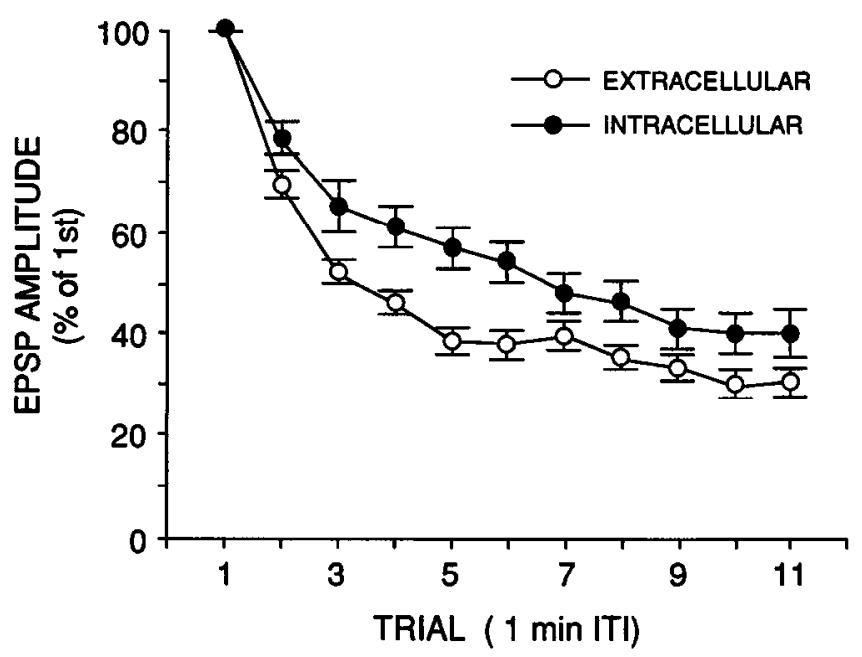

Figure 4. Homosynaptic depression is greater when the sensory neuron is not impaled. Depression was evoked either by extracellular stimulation $(n=19)$ or intracellular stimulation $(n=13$, data replotted from Fig. $2 B$ ). Average EPSP amplitude at trial 1 was $39.5 \pm 4.4 \mathrm{mV}$ in the extracellular group and $43.8 \pm 3.5 \mathrm{mV}$ in the intracellular group.

many different synapses (Eusebi et al., 1986; Malenka et al., 1986; Yamamoto et al., 1987).

To test the role of protein kinase C in PTP, we used the blocker H7 (Seikagaku, Japan). This inhibitor, which is only modestly selective for protein kinase $C$ in vitro (Hidaka et al., 1984), has nonetheless been demonstrated in intact sensory neurons to block phorbol ester-stimulated processes without altering cAMPmediated effects (Braha et al.. 1993). When we applied $200 \mu \mathrm{M}$ H7 (the same concentration used by Braha et al.) to depressed synapses shortly before sensory neuron tetanization, PTP was not affected. One minute after tetanus, synapses were facilitated by $2.46 \pm 0.47$-fold $(n=5)$ in the presence of $\mathrm{H} 7$ as compared to $2.60 \pm 0.34$-fold facilitation $(n=6)$ in its absence (Fig. $8 \mathrm{~A}$ ). In contrast, briefly applying the same concentration of $\mathrm{H}_{7} 2$ min after tetanization dramatically reduced the EPSP to its pretetanus level. This result might suggest that protein kinase $C$ participates in the maintenance, but not the initial induction of PTP. However, $\mathrm{H} 7$ had a similar effect on synaptic transmission from sensory neurons that had not been tetanized (Fig. $8 B)$.

These results indicate that protein kinase $C$ activation is not necessary for PTP. The general depressive effect of $\mathrm{H} 7$ on synaptic transmission may be nonspecific, or it might also reflect a role of protein kinase $C$ in basal transmitter release or vesicle mobilization. This seems plausible in light of a number of reports that activation of protein kinase $C$ facilitates both evoked and spontaneous release (Eusebi et al., 1986; Shapira et al., 1987; Ghirardi et al., 1992; Sugita et al., 1992).

Homosynaptic depression affects neither the amplitude nor the frequency of spontaneous $m E P S P S$ or $M E P S C s$

Homosynaptic depression has been demonstrated in the ganglion to be mediated by a decrease in quantal content, with no change in quantal size (Castellucci and Kandel, 1974). Analysis of spontaneous release in culture allows a second method for quantal analysis of synaptic depression. Another and perhaps more novel use of spontaneous release is to address the issue of vesicle depletion during synaptic depression.

Spontaneous release was analyzed during synaptic depression 


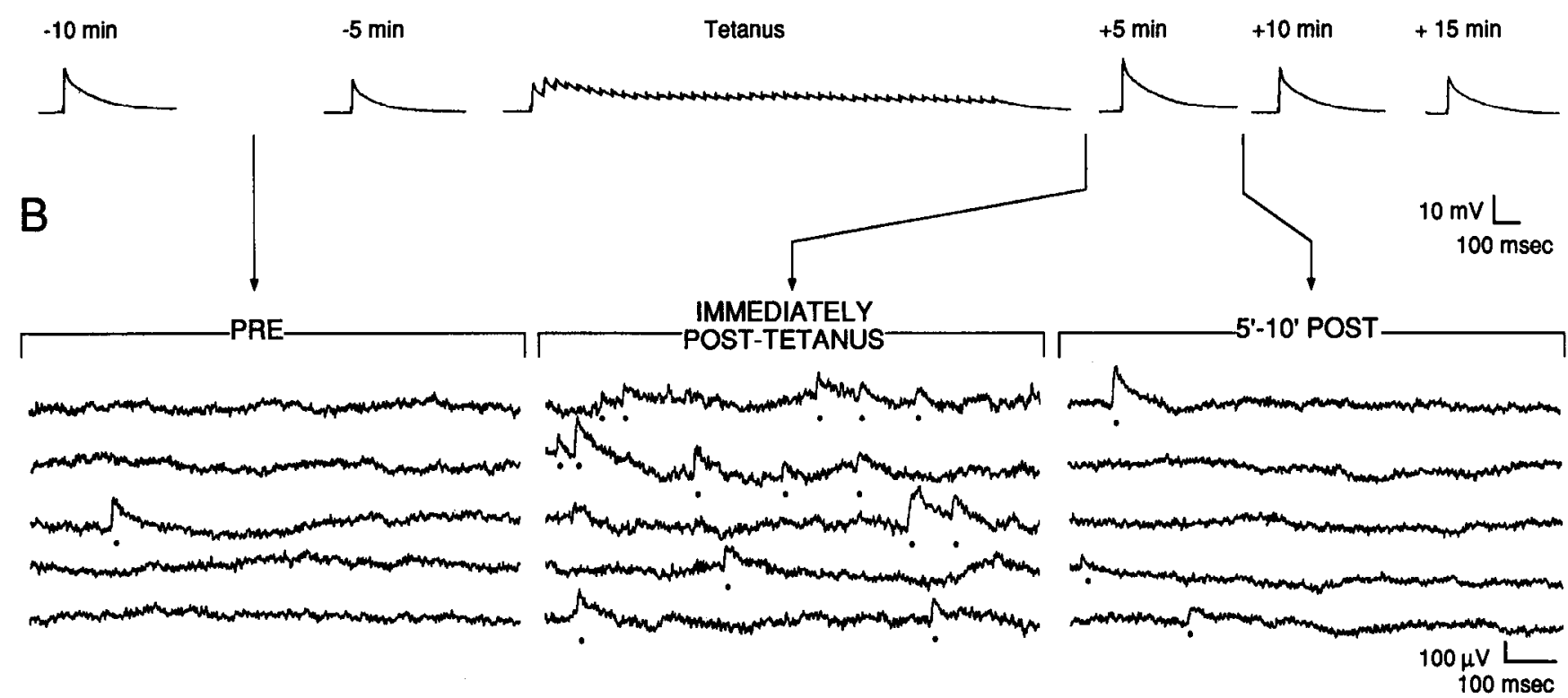

Figure 5. PTP is accompanicd by an enhancement of spontancous relcase. Recordings of evoked $(A)$ and spontaneous $(B)$ release in an $\mathrm{L} 7$ synapse during PTP. mEPSP frequency is substantially enhanced immediately after tetanus $(20 \mathrm{~Hz})$, and remains somewhat elevated for the duration of evoked facilitation. mEPSPs are indicated by dots.

using two different stimulation protocols. In the first, depression was produced by stimulating extracellularly with single action potentials at $5 \mathrm{~min}$ intervals, and $\mathrm{mEPSP}$ or $\mathrm{mEPSC}$ frequency was compared in the intervening intervals. As can be seen from the test-only controls in Figure $3 A$, sensory neuron synapses depress substantially, even at 5 min stimulation intervals. In 20 experiments, the EPSP was reduced to an average of $71 \pm 1 \%$ of its starting value by the third stimulus, whereas the frequency of spontaneous release was unaltered (Fig. 9). The relationship between depression and spontancous release frequency in individual experiments is plotted in Figure $10 \mathrm{~A}$. There is no correlation between changes in spontaneous and evoked release.

These experiments also provide an opportunity to test for changes in quantal size with depression. Mini amplitude does not decrease during depression of the evoked EPSP at $5 \mathrm{~min}$ intervals (Fig. 10B). Average mini size instead slightly increased in these experiments, but the effect was not significant $(+4.9 \pm$ $4.7 \%$ change, $p>0.10$ ). These results confirm the finding of Castellucci and Kandel (1974) that sensory neuron depression is presynaptic, a reduction in evoked release without a change in postsynaptic responsiveness or vesicle loading.

The second protocol used to test for depletion during homosynaptic depression employed extensive stimulation at $1 \mathrm{~Hz}$. While stimulation at 5 min intervals reliably depressed the synapse, it is possible that depletion only plays a role in more extensive depression, after a number of action potentials have been evoked. mEPSCs were recorded in LFS cells under wholecell voltage clamp before and after 80-120 sec of sensory neuron stimulation at $1 \mathrm{~Hz}$. Such extensive stimulation profoundly depresses the evoked EPSP, but has relatively little effect on spontaneous release (Fig. 11). Group data from five similar experiments are plotted in Figure 12. Stimulation reduces the EPSP to an average of $11 \pm 3 \%$ of its starting amplitude. In contrast, the frequency of spontaneous release is unaffected, except im- mediately after the end of stimulation. While stimulation has an overall effect on the rate of spontaneous release $\left(F_{5.20}=4.14\right.$, $p<0.01$ ), mini frequency is only significantly reduced (to 51.8 $\pm 9.8 \%$ of resting frequency) in the first $30 \mathrm{sec}$ interval after stimulation $(p<0.05$, Dunnett's test). It recovers almost completely by $1 \mathrm{~min}$ after stimulation and does not significantly differ from resting frequency in this or any later interval. In contrast, even 4 min after the end of stimulation, the evoked EPSP remains substantially depressed, to $42.7 \pm 9.8 \%$ of its starting amplitude $(t=3.89, p<0.02)$. As in the cxpcriments using stimulation at 5 min intervals, the size of unitary mEPSCs was not reduced by extensive depression of the evoked EPSP.

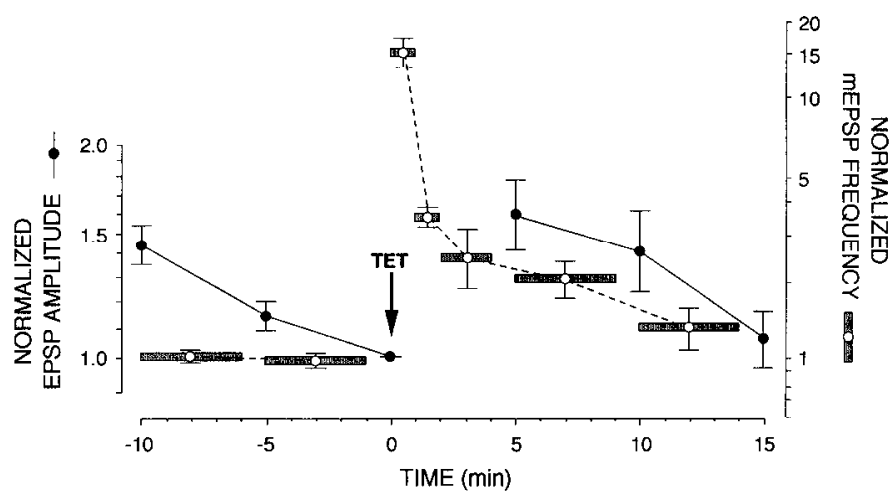

Figure 6. The decay of mEPSP frequency parallels the decay of PTP. Group data are from five experiments like the one illustrated in Figure 6. Horizontal bars indicate the interval over which mEPSP frequency was sampled for each data point. The tetanus was delivered at the arrow. Although the increase in mEPSP frequency is many times larger than the increase in EPSP amplitude, both are significant through $10 \mathrm{~min}$ posttetanus, but not later. In this and subsequent figures, evoked EPSP amplitude is normalized to the first EPSP of the tetanus, and mEPSP frequency is normalized to the average of both intervals before the tetanus. Note the log scales for both y-axes. 


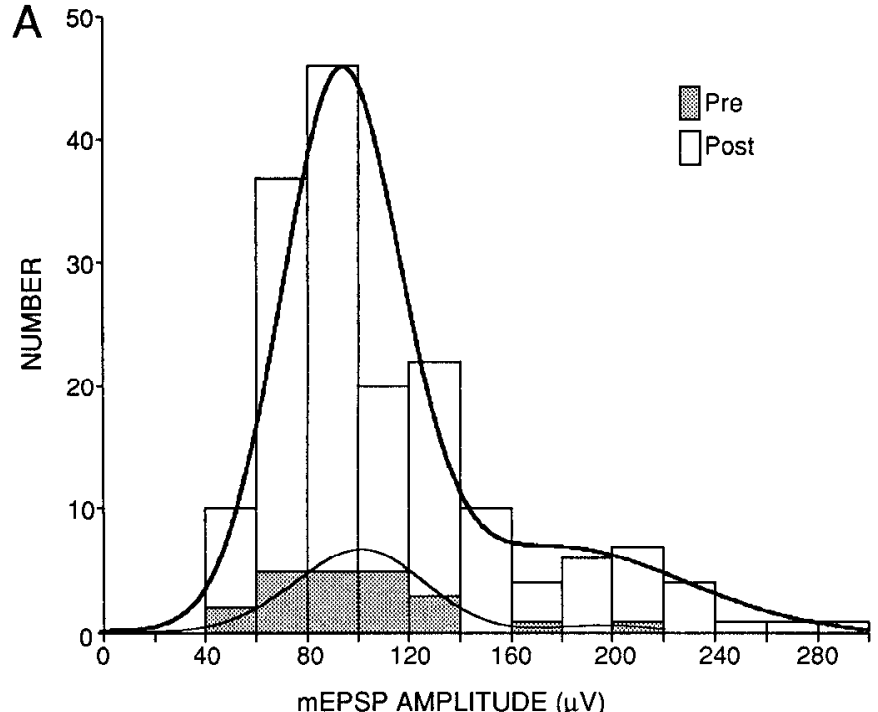

B

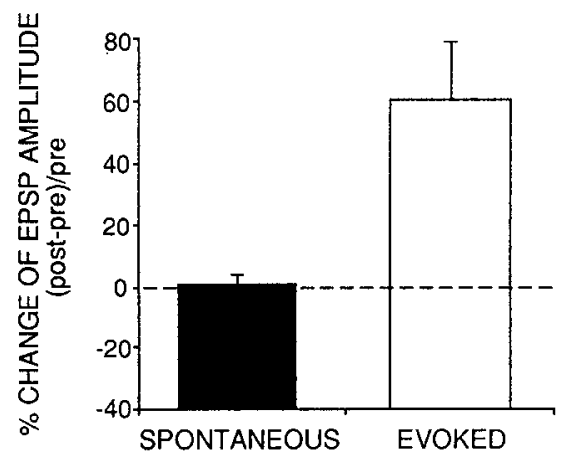

Figure 7. Tetanus does not change the amplitude of spontaneous mEPSPs. $A$, Distribution of mEPSP amplitudes in all intervals before and after tetanus for the experiment shown in Figure 5. The mean unitary size was $91.5 \pm 23.7 \mu \mathrm{V}$ before tetanus and $90.2 \pm 22.9 \mu \mathrm{V}$ after tetanus, determined by fitting two Gaussian distributions to each set. $B$. Group data illustrating that mean amplitude of the unitary mEPSP does not change following tetanus whereas the evoked EPSP is significantly elevated $(p<0.005)$. The change in evoked amplitude is the average of EPSP amplitudes at 5 and $10 \mathrm{~min}$ posttetanus $(n=4$, because in one of the five experiments, there were too few mEPSPs before the tetanus to fit a Gaussian distribution). Average unitary mEPSP amplitude was $70.8 \pm 7.2 \mu \mathrm{V}$ before tetanus, and $71.0 \pm 7.0 \mu \mathrm{V}$ after tetanus.

Average unitary mEPSC amplitude was $14.1 \pm 2.6 \mathrm{pA}$ in all intervals before depression compared to $15.5 \pm 2.8 \mathrm{pA}$ in all intervals after stimulation (average change was $+11.5 \pm 5.6 \%$, $n=5$, NS).

These findings are consistent with our results on depression at 5 min intervals. Depression cannot be accounted for either by changes in mini amplitude or frequency. Extensive stimulation does briefly reduce the frequency of spontaneous mEPSCs, indicating that such changes can be detected, but the duration of the decrease does not parallel the depression of evoked release.

\section{Discussion}

Previous studies have established that homosynaptic depression and PTP are preserved when Aplysia sensory-motor synapses are reconstituted in culture (Rayport and Schacher 1986, Schacher et al., 1990). Here we further characterized these two
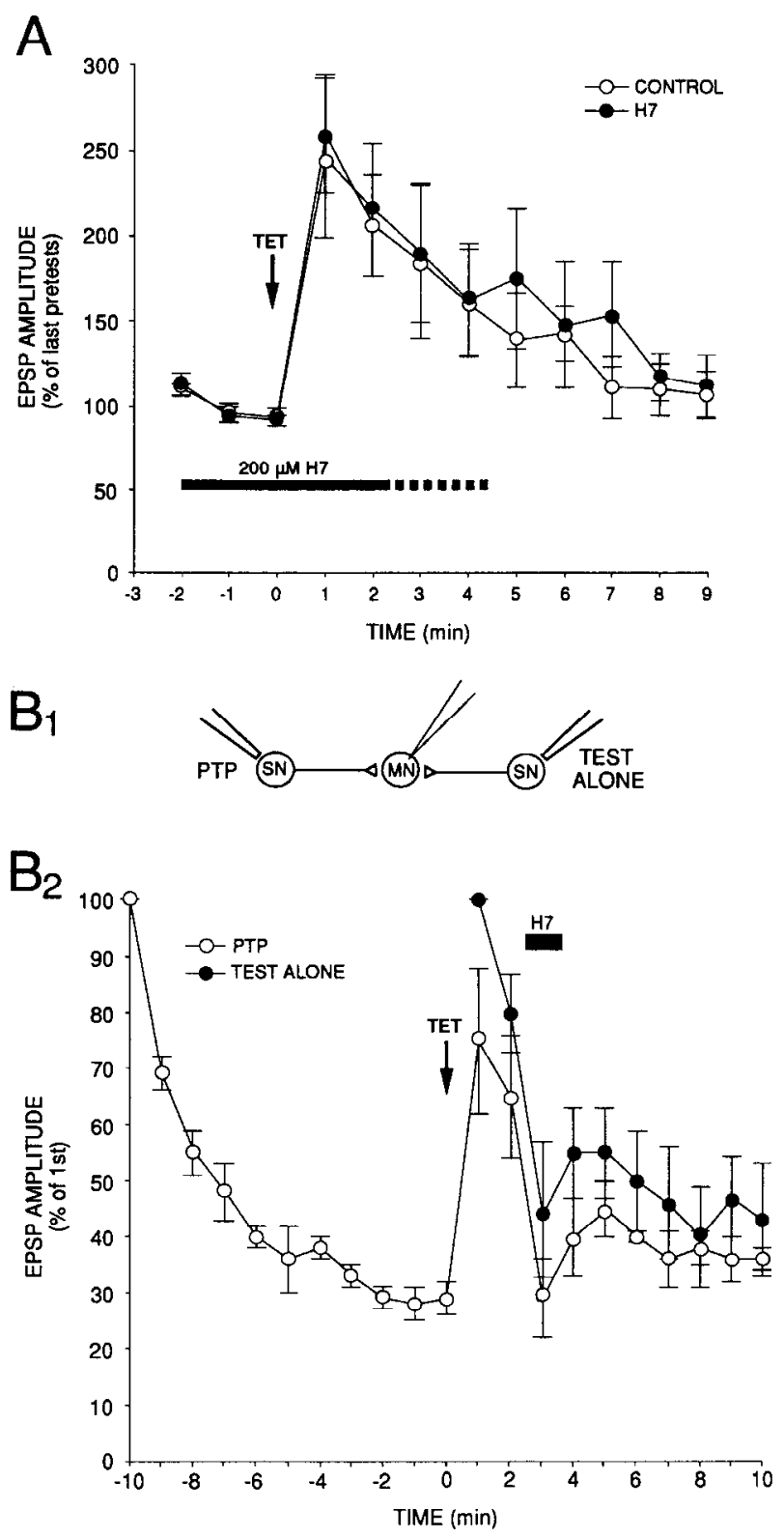

Figure 8. $\mathrm{H} 7$ blocks neither induction nor maintenance of PTP. $A$ Average results of five experiments in which PTP was induced in the presence of $\mathrm{H} 7$ and six control PTP experiments. In both groups, EPSPs were depressed to $25-30 \%$ of initial amplitude before receiving a $2 \mathrm{sec}$, $20 \mathrm{~Hz}$ extracellular tetanus (TET). Amplitudes were normalized to the average of tests at $-2,-1$, and 0 (first FPSP of the tetanus) min. $\mathrm{H} 7$ does not block PTP induction. $B_{l}$, Diagram of experimental protocol used to test the effect of $\mathrm{H} 7$ on PTP maintenance. Cultures containing two sensory neurons synapsing on a common LFS motor neuron were used. After pretesting, one cell $(P T P)$ received the same tetanus used in $A$. Stimulation of the second sensory cell (TEST ALONE) began only after the first cell was tetanized. $B, H 7$ reduces synaptic transmission of both facilitated and control EPSPs. Results are average of five experiments as depicted in $B_{l}$. H7 $(200 \mu \mathrm{M})$ was applied for $1 \mathrm{~min}$, beginning $2.5 \mathrm{~min}$ after the tetanus, by microperfusion. The effect is not a perfusion artifact because cells were similarly perfused with normal saline both before and after $\mathrm{H} 7$ application.

forms of plasticity and exploited the ability to measure spontaneous transmitter release from a single presynaptic sensory neuron in culture to analyze further the mechanisms underlying depression and PTP. 


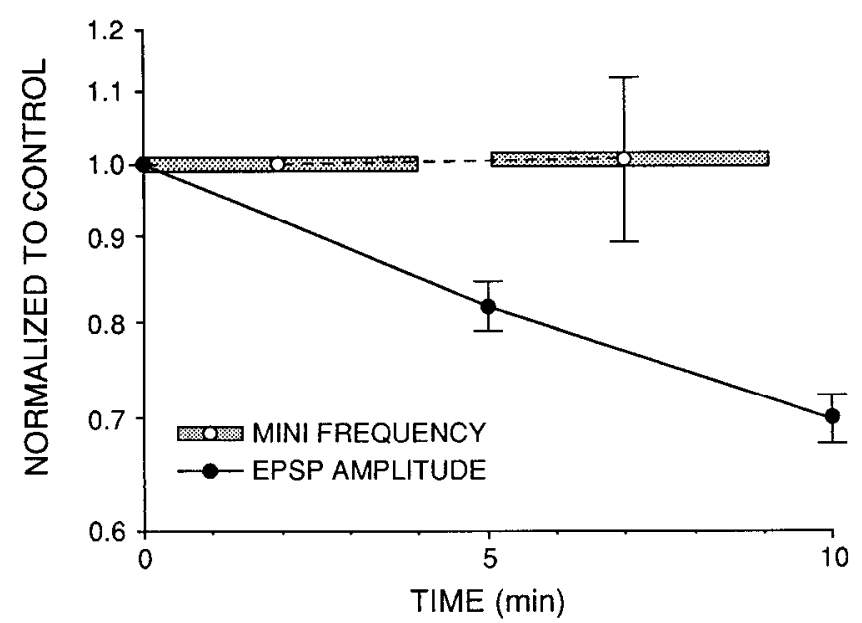

Figure 9. Modest depression does not alter spontaneous release frequency. Results are average of 20 experiments in which the EPSP was elicited once every $5 \mathrm{~min}$ using extracellular stimulation, and spontaneous release frequency was measured in the intervening intervals (five of these experiments are from Fig. 6).

We found that changes in mini amplitude cannot account for either form of plasticity (Figs. 7, 10B), suggesting that both depression and PTP are presynaptically mediated. One class of presynaptic mechanism proposed to underlie short-term homosynaptic plasticity involves changes in the availability of vesicles for release: vesicle "mobilization" in the case of PTP and depletion in the case of depression (Gingrich and Byrne, 1985). We therefore looked for changes in spontaneous release frequency that might provide evidence for such changes in vesicle availability.

\section{PTP and depression in culture}

Homosynaptic depression exhibits very similar properties in culture compared to those in the ganglion (Byrne, 1982). The largest increment of depression occurs between the first and second EPSPs. Shorter stimulus intervals produce more profound depression (Fig. 1). PTP also exhibits similar magnitude and kinetics in culture and in the ganglion (Clark and Kandel, 1984; Walters and Byrne, 1984). These findings indicate that the mechanisms underlying both forms of homosynaptic plasticity are intrinsic to the synapse and do not importantly involve additional neural circuitry.

The only discrepancy we observed is that PTP does not occur in culture when the sensory neuron is impaled with an intracellular microelectrode. Impalement has been observed to increase levels of somatic $\mathrm{Ca}^{2+}$ in cultured cerebellar Purkinje cells, an effect that takes a number of minutes to recover (Connor and Tseng, 1988). Four findings suggest that a similar elevation of intracellular $\mathrm{Ca}^{2+}$ occurs when cultured sensory neurons are impaled: (1) the frequency of spontaneous release is higher in impaled cells; (2) evoked EPSP amplitude increased after impalement in a few cases (not shown); (3) depression is less profound with intracellular as compared to extracellular stimulation (Fig. 4), suggesting that impalement promotes some $\mathrm{Ca}^{2+}$-dependent mobilization process; and (4) the loss of PTP can be reversed after removing the intracellular electrode if adequate time is allowed for recovery. Presumably, elevated intracellular $\mathrm{Ca}^{2+}$ interferes with PTP by dampening the increase in $\mathrm{Ca}^{2+}$ produced by tetanus. Sensory neurons in the ganglion appear
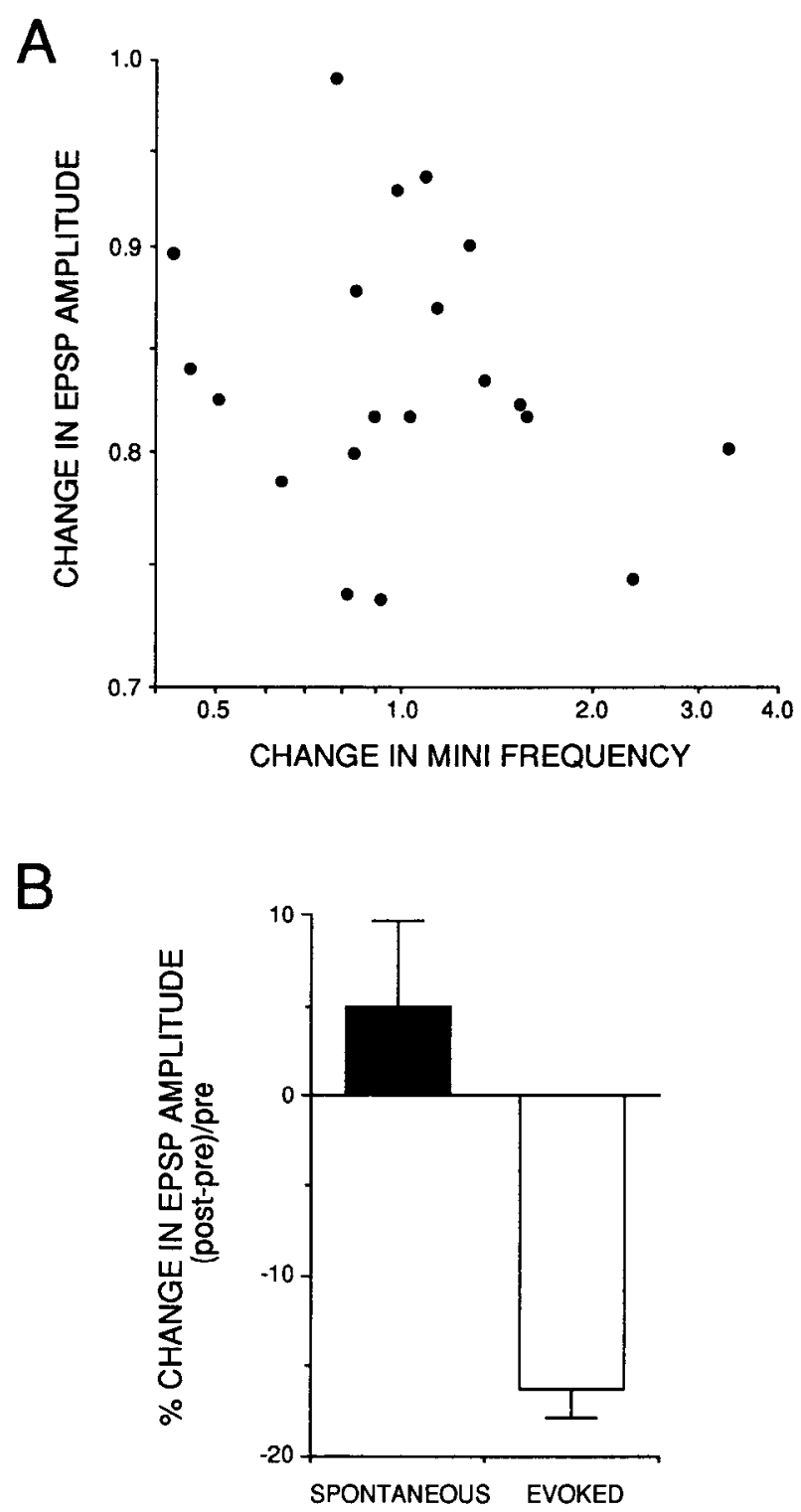

Figure 10. Modest depression is not associated with changes in mini frequency or amplitude. $A$, Relationship between mini frequency and evoked depression in individual experiments from Figure $9(R=-0.22)$. Mini frequency in the interval from 5 to $10 \mathrm{~min}$ is normalized to the frequency from 0 to $5 \mathrm{~min}$. Average EPSP amplitude at 5 and $10 \mathrm{~min}$ is normalized to the average at 0 and $5 \mathrm{~min}$. $B$, A change in unitary size does not account for evoked depression. Average amplitude of spontaneous mEPSPs or mEPSPs in the interval from 5 to $10 \mathrm{~min}$ is normalized to the interval from 0 to $5 \mathrm{~min}$. The EPSP is significantly depressed $(p<0.001)$ whereas the change in mini amplitude is not significant. The number of minis in each interval was too small to fit amplitude distributions, so average amplitudes were used to calculate changes. Thus, the small increase in mini amplitude could be due to an increased incidence of multiple quantal events. For $L 7$ synapses, average mEPSP amplitude was $107.5 \pm 14.0 \mu \mathrm{V}$ in the first interval and 107.3 $\pm 11.8 \mu \mathrm{V}$ in the second interval, $n=12$; for LFS synapses, mEPSC amplitude averaged $24.8 \pm 4.2 \mathrm{pA}$ in the first interval and $25.5 \pm 4.2$ $\mathrm{pA}$ in the second interval $(n=8)$.

not to suffer this impalement effect, because they exhibit robust PTP following intracellular tetanization (Clark and Kandel, 1984; Walters and Byrne, 1984). The difference may be due to the greater distance between the soma and presynaptic terminals in sensory neurons in the ganglion as compared to in culture. 


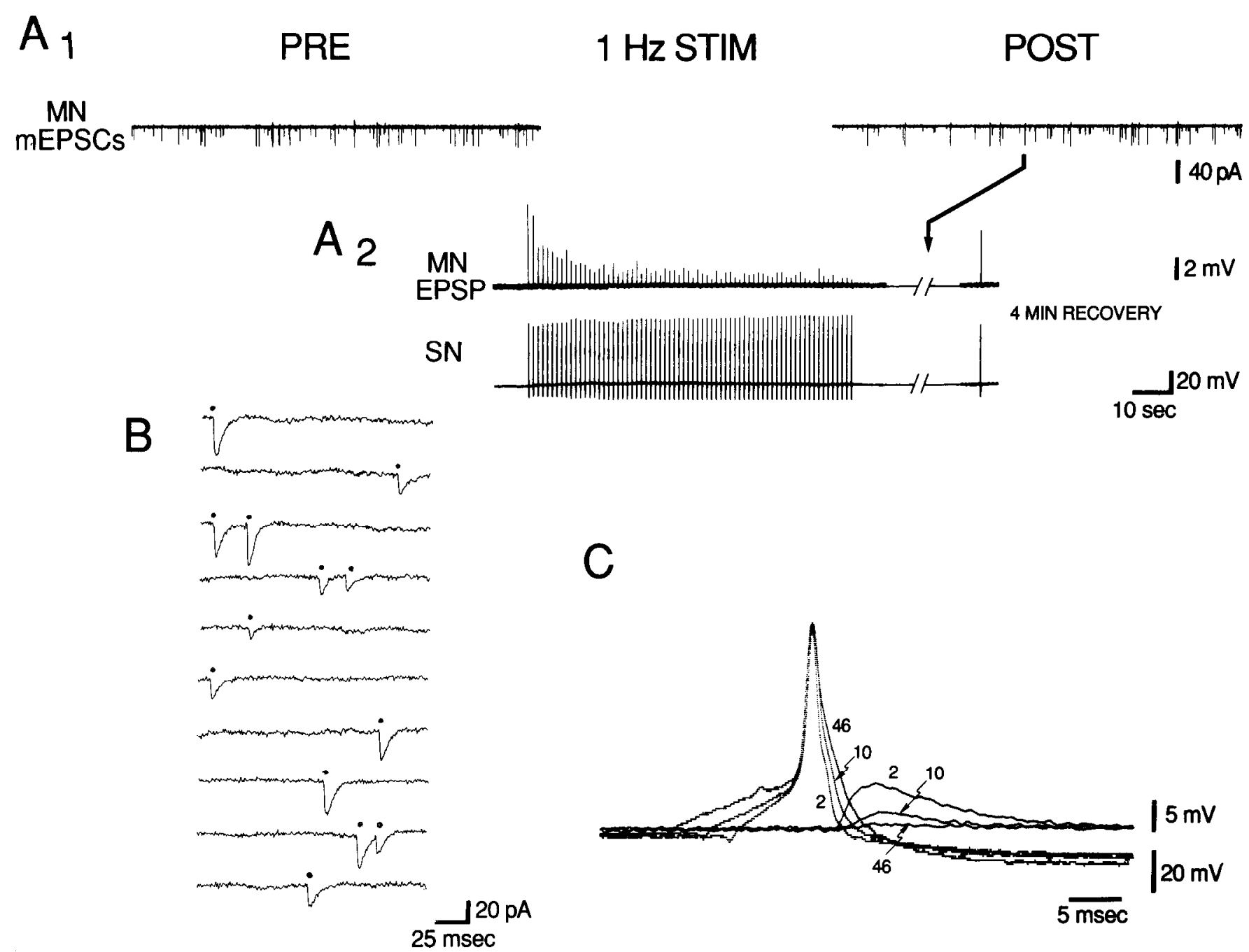

Figure 11. Extensive stimulation reduces both EPSP amplitude and mEPSC frequency, but spontaneous release recovers quickly, while evoked release does not. $A$, mEPSCs measured in an LFS cell $(M N)$ under voltage clamp before and after $\mathrm{l} \mathrm{Hz}$ stimulation of the sensory neuron. Note that mEPSC frequency is reduced only for the first $30-40 \mathrm{sec}$ poststimulation. $A_{2}$, Voltage recording in the LFS cell during intracellular stimulation of the sensory neuron at $1 \mathrm{~Hz}$. The first EPSP produced a spike in the motor neuron that was off scale at this gain. The gap in the record indicates the $4 \mathrm{~min}$ interval between the end of stimulation and the frrst test for recovery of the EPSP. $B$, Examples of mEPSCs recorded during the prestimulation interval in $A_{1}$. Sweeps containing mEPSCs (indicated by dots) were selected, because at this expanded time scale, many of the sweeps would be empty. This figure illustrates the waveform of mEPSCs in an LFS synapse and is not meant to depict actual frequency, which is considerably lower. $C$. Expanded recordings of three synaptic responses from $A_{2}$. Note that the EPSP undergoes depression despite presynaptic spike broadening during the train, consistent with depletion playing a role in depression during the train.

\section{Mechanisms underlying PTP in cultured synapses}

Spontaneous mF.PSPs measured before and after PTP induction showed no change in unitary amplitude (Fig. 7). This result agrees with quantal analyses of PTP at a number of other synapses (Liley, 1956; Hirst et al., 1981; Clamann et al., 1989; Griffith, 1990). Sensory neuron PTP is evidently mediated by an increase in release, rather than a change in postsynaptic responsiveness to transmitter.

In contrast to its lack of effect on quantal size, PTP produced a large enhancement in the frequency of spontaneous release. mEPSP frequency was elevated 15 -fold in the $1 \mathrm{~min}$ interval following tetanization (Fig. 6). This enhancement appears to decay with both fast and slow components, perhaps reflecting the same augmentation and potentiation phases of evoked and mEPSP facilitation seen at the neuromuscular junction (Zengel and Maglcby, 1981). Although we did not test evoked release shortly after tetanus in these experiments, comparison to Figure
$3 A$ suggests that the initially large enhancement in mini frcquency is only partially reflected in facilitation of evoked release at 1 min posttetanus. However, the slower phase of mEPSP frequency decay appears to parallel closely the decay of evoked EPSP facilitation. Both mEPSP frequency and EPSP amplitude remained significantly increased over pretetanus levels for 10 min, but not at later time points. This parallel between the pustletanus frequency of spontaneous release and facilitation of evoked release has been observed at neuromuscular synapses (Liley, 1956; Lev-Tov and Rahamimoff, 1980; Zengel and Magleby, 1981; Zucker and Lara-Estrella, 1983), and suggests that PTP is mediated by a mechanism common to both forms of release - that is, some process independent of excitation-secretion coupling. This finding is consistent with the model that high-frequency stimulation "mobilizes" vesicles, in some way making them more available for release (Gingrich and Byrne, 1985).

PTP at sensory-motor neuron synapses thus appears to be 
quite similar to PTP at the neuromuscular junction and other synapses. One notable difference is the longer duration of sensory neuron PTP (up to $10 \mathrm{~min}$ ) produced by fewer spikes than at other well-studied synapses. For example, the same $20 \mathrm{~Hz}$, $2 \mathrm{sec}$ tetanus produces facilitation with 47 and $130 \mathrm{msec}$ time constants at the crayfish neuromuscular junction (Zucker and Lara-Estrella, 1983), and a 100 times larger tetanus $(200 \mathrm{~Hz}$ for $20 \mathrm{sec}$ ) produces PTP that lasts only $80 \mathrm{sec}$ at spinal cord $1 \mathrm{~A}$ afferent synapses (Hirst et al., 1981). This difference, together with the fact that sensory neurons show profound depression to very low frequency stimuli, indicates that Aplysia sensory neurons are exquisitely sensitive to their recent history of activity.

PTP is well known to involve $\mathrm{Ca}^{2+}$ influx during the tetanus (Rosenthal, 1969; Weinreich, 1971). Various measures indicate that $\mathrm{Ca}^{2+}$ accumulates during trains of action potentials, and that the decay of $[\mathrm{Ca}]$, is closely related to the decay of potentiation (Kretz et al., 1982; Connor et al., 1986; Delaney et al., 1989; Regehr and Tank, 1991; Swandulla et al., 1991). Moreover, preventing $\mathrm{Ca}^{2+}$ buildup with EGTA and other chelators blocks PTP (Kretz et al., 1982; Swandulla et al., 1991). Such findings support the early proposal that PTP is due to residual $\mathrm{Ca}^{2+}$ in the nerve terminal (Gage and Hubbard, 1966; Rosenthal, 1969; Miledi and Thies, 1971; Weinreich, 1971; Magleby and Zengel,' 1975). In these early formulations, residual $\mathrm{Ca}^{2+}$ was thought to act directly on the $\mathrm{Ca}^{2+}$-activated release machinery. More recent assessments suggest a different possibility. Transmitter release is now thought to be mediated by lowaffinity $\mathrm{Ca}^{2}+$ binding sites requiring very high $(>100 \mu \mathrm{m})$ local [Ca $]_{i}$ (Simon and Llinas, 1985; Adler et al., 1991; Roberts et al., 1991; Yamada and Zucker, 1992), whereas PTP is considerably more sensitive to $[\mathrm{Ca}]_{i}$, varying approximately linearly with [Ca], in the submicromolar range (Delaney et al., 1989; Regehr and Tank, 1991; Swandulla et al., 1991). These findings suggest that residual $\mathrm{Ca}^{2}$ ' does not act directly on the exocytotic machinery but at another site, for example, a $\mathrm{Ca}^{2+}$-dependent enzymatic reaction that modulates release by another mechanism.

The long duration of sensory neuron PTP seems especially to favor a mechanism whereby $\mathrm{Ca}^{2+}$ influx triggers a biochemical cascade producing facilitation, as opposed to residual $\mathrm{Ca}^{2+}$ acting directly on release. Various $\mathrm{Ca}^{2+}$-dependent enzymes have been hypothesized to play such a role in PTP. Protein kinase $\mathrm{C}$ is one candidate, given the $\mathrm{Ca}^{2+}$ dependence of some of its isoforms, and the fact that it enhances both spontaneous and evoked release from many different synapses. However, our evidence indicates that protein kinase $C$ activation is not necessary for the induction of PTP (Fig. 8A). Similar results have been reported for PTP in hippocampal slices using two other inhibitors of protein kinase C, polymixin B and K-252b (Reymann et al., 1988a,b). $\mathrm{H} 7$ did reverse facilitation 2 min posttetanus in our experiments, but it had a comparable effect on basal synaptic transmission, indicating that the effect is not specific to PTP (Fig. 8B). Other studies have also reported some reduction of basal synaptic transmission by $\mathrm{H} 7$ (Malinow et al., 1988; Muller et al., 1988). These effects could be specific, reflecting a role of basal protein kinase $\mathrm{C}$ activity in synaptic transmission, or they could be nonspecific, for example, due to $\mathrm{H} 7$ blocking postsynaptic transmitter receptors (Hirsh et al., 1990; Leidenheimer et al., 1990; Amador and Dani, 1991; Reuhl et al., 1992). Since Ghirardi et al. (1992) found no cffect of H7 on sensory neuron transmission onto $\mathrm{L} 7$ motor neurons, its

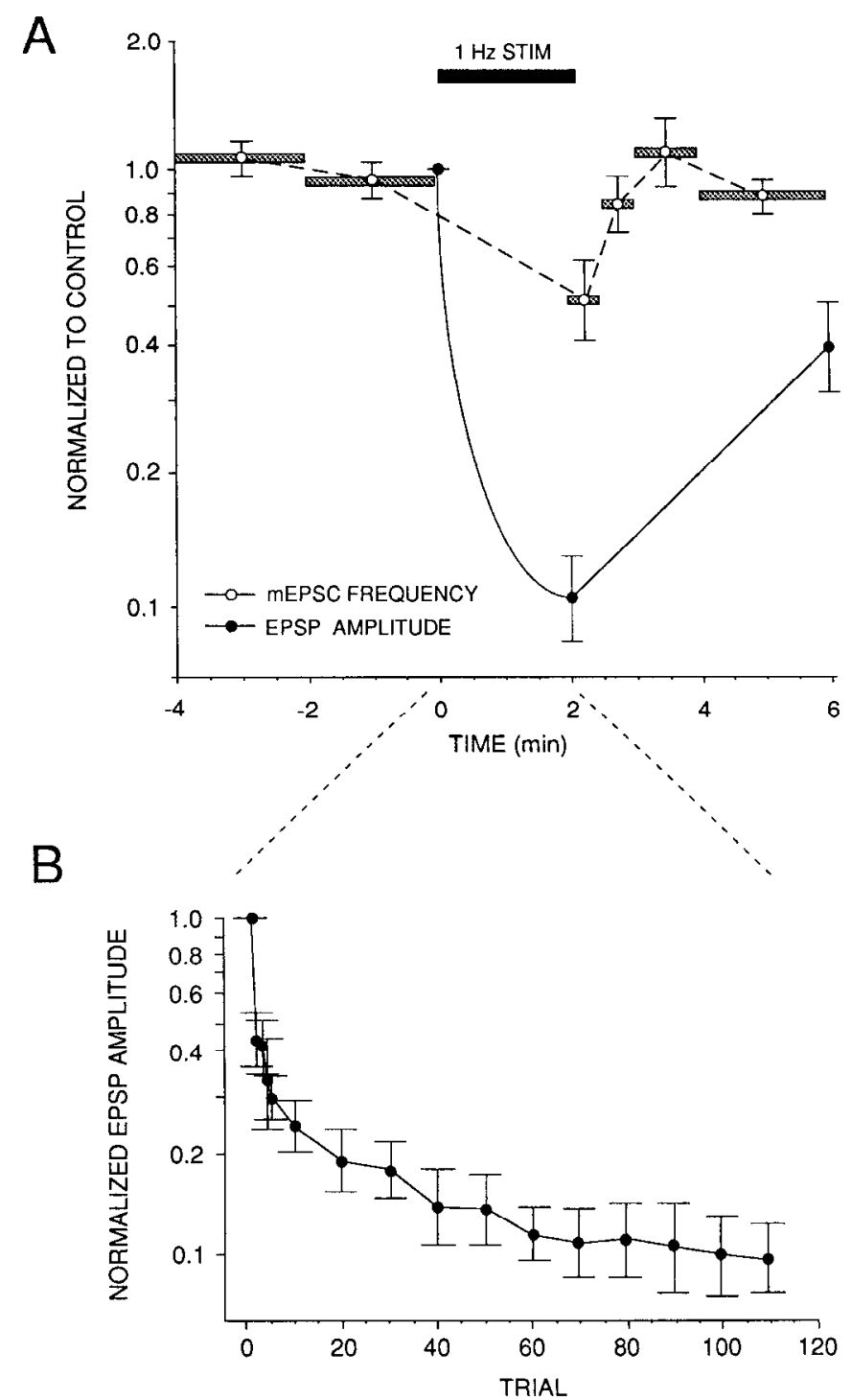

Figure 12. Depression of evoked release is more profound and lasts longer than the decrease in mEPSC frequency following $1 \mathrm{~Hz}$ stimulation. $A$, Group data from five experiments like the one shown in Figure 11. Evoked release is profoundly depressed by stimulating at $1 \mathrm{~Hz}$ for $120 \mathrm{sec}(80 \mathrm{sec}$ in one experiment). By $4 \mathrm{~min}$ after the end of stimulation, the evoked EPSP has partially recovered, but remains significantly depressed compared to its initial amplitude. In contrast, mEPSC frequency is reduced for only the first $30 \mathrm{sec}$ following stimulation, and fully recovers after that. Horizontal hars indicate the interval over which mEPSC frequency was sampled for each data point. For clarity, only the first and average of the last 10 evoked EPSPs of the train are depicted in $A$. The full course of evoked EPSP depression during I Hz stimulation is plotted in $B$, which shows the first five trials, followed by the average of groups of 10 trials.

inhibition of transmission onto LFS synapses observed here may be due to such a postsynaptic effect.

Two other candidate enzymes for a role in PTP are cAMPdependent kinase and $\mathrm{Ca}^{2+} /$ calmodulin-dependent kinase (CaM kinase). Although the cAMP-dependent kinase itself is not $\mathrm{Ca}^{2+}$ dependent, $\mathrm{Ca}^{2+} /$ calmodulin stimulates adenylate cyclase, especially cyclase in the nervous system (Eliot et al., 1989), and cAMP increases evoked release in sensory neurons (Brunelli et al., 1976; Braha et al., 1990). However, we recently demonstrated that the same $20 \mathrm{~Hz}, 2$ sec tetanus has no effect on either 
sensory neuron excitability or action potential width, both of which are sensitive to cAMP levels in sensory neurons (Eliot et al., 1994), suggesting that activity alone does not activate adenylate cyclase.

CaM kinase may thus be a better candidate for a role in PTP. At the squid giant synapse, CaM kinase increases transmitter release in a $\mathrm{Ca}^{2+}$-dependent manner, apparently by mobilizing vesicles for release (Llinas et al., 1985; Lin et al., 1990). A recent study showing reversible blockade of PTP by a specific peptide inhibitor directly implicates CaM kinase at the squid synapse (M. Hans, D. Swandulla, and G. J. Augustine, unpublished observations). If CaM kinase mediates PTP in Aplysia, however, it must be somewhat different from the CaM kinase in squid and hippocampal preparations, which are blocked by $\mathrm{H} 7$ (Malinow et al., 1988; Hans, Swandulla, and Augustine, unpublished observations).

\section{Depletion may not be the primary mechanism of homosynaptic depression}

Like depression in the ganglion, homosynaptic depression in culture is evidently presynaptically mediated. mEPSC or mEPSP size did not decrease when the EPSP was significantly depressed (Fig. 10B). This was true both for modest depression induced by stimulation at $5 \mathrm{~min}$ intervals and for profound depression induced by stimulation at $1 \mathrm{sec}$ intervals. These results agree with previous studies on short-term synaptic depression (del Castillo and Katz, 1954; Castellucci and Kandel, 1974) demonstrating that depression is due to a decrease in quantal content, but not in quantal size.

The dominant hypothesis for the presynaptic mechanism of depression at the vertebrate neuromuscular junctions is vesicle depletion (reviewed in Zucker, 1989). Depletion has also been proposed as one of the mechanisms contributing to depression of sensory neuron synapses (Gingrich and Byrne, 1985). Since PTP in sensory neurons is accompanied by an increased frequency of spontaneous release, suggesting it is mediated by vesicle mobilization, it seemed likely that depression would be associated with a decreased frequency of spontaneous release as a consequence of vesicle depletion. We therefore looked for changes in mini frequency during depression as an assay for vesicle depletion. This approach assumes that evoked and spontaneous release are mediated by a common pool of vesicles, which is supported by their parallel modulation during PTP as well as during four other instances of plasticity in sensory neurons: both are (1) increased by $5-\mathrm{HT},(2)$ decreased by the tetrapeptide FMRF (Dale and Kandel, 1990), (3) increased by phorbol esters (Braha et al., 1990; Ghirardi et al., 1992), and (4) increased by tonic depolarization due to $\mathrm{Ca}^{2+}$ influx through L-type channels (Edmonds et al., 1990). Such parallel modulation suggests that the pool of vesicles released spontaneously is the same as the pool of vesicles released by action potentials. If depression of evoked release is due to vesicle depletion, it may then be detectable as a decrease in mini frequency.

We did detect a decrease in spontaneous release in one instance of depression-immediately following fairly extensive stimulation (80-120 spikes at $1 \mathrm{~Hz}$; Fig. 12). This $50 \%$ decrease occurs in spite of a 20-70 nM elevation of resting presynaptic $\mathrm{Ca}^{2+}$ measured in imaging experiments during the same $30 \mathrm{sec}$ time period immediately following the same stimulation protocol (Eliot, 1991). Since elevated [Ca], generally increases the probability of release, the fact that mEPSC frequency is reduced at a time when resting $\mathrm{Ca}^{2+}$ is actually enhanced suggests that the number of available vesicles is truly limiting, or depleted, for the first $30 \mathrm{sec}$ after stimulation. This conclusion is consistent with morphological evidence that the number of vesicles directly apposed to presynaptic active zones is reduced immediately after extensive sensory neuron stimulation (Bailey and Chen, 1988).

In contrast to this apparent depletion that occurs immediately after extensive stimulation, mini frequency recovers rapidly, and well in advance of evoked release (Fig. 12). This finding is similar to two other situations in which depression of evoked release was not paralleled by a change in mini frequency. First, stimulation at $5 \mathrm{~min}$ intervals reduces evoked release without altering spontaneous release frequency (Fig. 9). Second, in PTP experiments, spontaneous release frequency was maximal immediately after tetanization, even though evoked release was substantially depressed at the end of the tetanus (Fig. 5).

Depletion thus appears to contribute significantly to depression only during and immediately after extensive stimulation. Although Bailey and Chen (1988) saw a reduced number of vesicles adjacent to the active zone immediately after stimulation, they did not look at later time points. Indeed, the rapid recovery of spontaneous release we observed may be explained by their finding that the total number of vesicles in presynaptic terminals is not altered immediately after extensive stimulation, despite the decreased fraction at active zones (Bailey and Chen, 1988).

Taken together, our spontaneous release data suggest that depletion is not the primary mechanism of synaptic depression in sensory neurons. However, this conclusion depends on the assumption that evoked and spontaneous release are mediated by the same pool of vesicles. While the above-cited instances of parallel modulation support this assumption, it is possible that evoked and spontaneously released pools of vesicles overlap without being identical. For example, if evoked release utilizes just a small subset of a common pool of releasable vesicles, this subset could be depleted during depression without detectably depleting the total pool. This could occur, for example, if evoked rclcasc uses only a small fraction of the total number of presynaptic terminals, whereas spontaneous release occurs from most or all terminals. Alternatively, the evokable subset could be the vesicles immediately apposed to the active zone in each terminal, as implicitly proposed by Bailey and Chen (1988), while spontaneous release might utilize the entire population of vesicles in each bouton. This possibility seems to require the additional assumption that refilling or redocking of the subset involved in evoked release is slow or in some way inactivated, since both our spontaneous release data and electron micrographs of depressed terminals suggest a large population of vesicles is available for this purpose.

\section{Other possible mechanisms contributing to presynaptic depression}

Sensory neuron depression differs in a fundamental way from depression in other synapses thought to be subject to depletion in that it does not vary with the starting level of transmitter release. At both the squid synapse (Kusano and Landau, 1975; Swandulla et al., 1991) and neuromuscular junction (del Castillo and Katz, 1954; Thies, 1965), depression is more profound when quantal content is increased by elevating extracellular $\mathrm{Ca}^{2+}$, while it is reduced or even, overridden by facilitation when release is reduced using low extracellular $\mathrm{Ca}^{2+}$ solutions. Sensory neuron depression, in contrast, occurs at all levels of release, 
whether due to changes in extracellular $\mathrm{Ca}^{2+}(\mathrm{Kandel}, 1976)$ or natural variation between synapses (Eliot, Kandel, and Hawkins, unpublished observations), and is thus less likely due to depletion. Zucker and Bruner (1977) reached a similar conclusion regarding depression at the crayfish fast flexor neuromuscular junction, which is similarly insensitive to starting level of release, shows kinetics of depression comparable to sensory neurons, and was found to be inadequately described by a depletion model.

The dissociation between evoked and spontaneous release in depression is similar to the case of pairing-specific, activitydependent facilitation at sensory neuron synapses. In the latter form of plasticity, evoked release was enhanced in an associative manner by pairing tetanus with 5-HT application, but spontaneous release exhibited no such associative enhancement (Eliot et al., 1994). This finding suggested that the associative mechanism involves processes unique to evoked relcasc and, indced, paired training was found to enhance broadening of the sensory neuron action potential, presumably increasing $\mathrm{Ca}^{2}+$ influx and, thereby, evoked release. The fact that mini frequency is not reduced during depression suggests that depression may also be mediated by a mechanism unique to evoked release or excitation-secretion coupling.

One mechanism that has already been implicated in sensory neurons is slow $\mathrm{Ca}^{2+}$ current inactivation (Klein et al., 1980). Reduction in $\mathrm{Ca}^{2+}$ current has also been correlated with synaptic depression in cultured dorsal root ganglion cells (Jia and Nelson, 1986). However, Pieroni and Byrne (1992) demonstrated depression in the absence of changes in tetraethylammoniumbroadened action potentials in sensory neurons, which should be a sensitive measure of total $\mathrm{Ca}^{2+}$ current. This issue thus needs to be reassessed by isolating and studying the inactivation properties of the dihydropyridine-insensitive, high-threshold $\mathrm{Ca}^{2+}$ current that underlies synaptic transmission in sensory neurons (Edmonds et al., 1990). Preliminary $\mathrm{Ca}^{2+}$ imaging studies support a reduction in $\mathrm{Ca}^{2+}$ influx with repeated activation, particularly when influx through these dihydropyridine-insensitive channels is isolated using the dihydropyridine antagonist, nitrendipine (Eliot, 1991). Alternatively, depression may be mediated by inactivation of excitation-secretion coupling-downstream from $\mathrm{Ca}^{2+}$ influx, such as a change in the $\mathrm{Ca}^{2+}$ dependence of vesicle docking or fusion. A better understanding of homosynaptic modulation may thus await a more complete description of the mechanism of exocytosis.

\section{References}

Adler EM, Augustine GJ, Duffy SN, Charlton MP (1991) Alien intracellular calcium chelators attenuate neurotransmitter release at the squid giant synapse. J Neurosci 11:1496-1507.

Amador M, Dani JA (1991) Protein kinase inhibitor, H-7, directly affects $N$-methyl-D-aspartate receptor channels. Neurosci Lett 124: 251-255.

Bailey CH, Chen M (1988) Morphological basis of short-term habituation in Aplysia. J Neurosci 8:2452-2459.

Braha O, Dale N, Hochner B, Klein M, Abrams TW, Kandel ER (1990) Second messengers involved in the two processes of presynaptic facilitation that contribute to sensitization and dishabituation in Aplysia sensory neurons. Proc Natl Acad Sci USA 87:2040-2044.

Braha O, Edmonds B, Sacktor T, Kandel ER, Klein M (1993) The contributions of protein kinase $\mathrm{A}$ and protein kinase $\mathrm{C}$ to the actions of 5-HT on the L-type $\mathrm{Ca}^{2+}$ current of the sensory neurons in Aplysia. J Neurosci 13:1839-1851.

Brunelli M, Castellucci V, Kandel ER (1976) Synaptic facilitation and behavioral sensitization in Aplysia: possible role of serotonin and cyclic AMP. Science 194:1178-1181.
Byrne JH (1982) Analysis of synaptic depression contributing to habituation of gill-withdrawal reflex in Aplysia californica. J Neurophysiol 48:431-438.

Byrne JH, Castellucci VF, Kandel ER (1978) Contribution of individual mechanoreceptor sensory neurons to defensive gill-withdrawal reflex in Aplysia. J Neurophysiol 41:418-431.

Castellucci VF, Kandel ER (1974) A quantal analysis of the synaptic depression underlying habituation of the gill-withdrawal reflex in Aplysia. Proc Natl Acad Sci USA 71:5004-5008.

Castellucci V, Pinsker H, Kupfermann I, Kandel ER (1970) Neuronal mechanisms of habituation and dishabituation of the gill-withdrawal reflex in Aplysia. Science 167:1745-1748.

Charlton MP, Bittner GD (1978) Presynaptic potentials and facilitation of transmitter release in the squid giant synapse. J Gen Physiol 72:487-511.

Charlton MP, Smith SJ, Zucker RS (1982) Role of presynaptic calcium ions and channels in synaptic facilitation and depression at the squid giant synapse. J Physiol (Lond) 323:173-193.

Clamann HP, Mathis J, Luscher H-R (1989) Variance analysis of excitatory postsynaptic potentials in cat spinal motoneurons during posttetanic potentiation. J Neurophysiol 61:403-416.

Clark GA, Kandel ER (1984) Branch-specific heterosynaptic facilitation in Aplysia siphon sensory cells. Proc Natl Acad Sci USA 81: 2577-2581.

Connor JA, Tseng H-Y (1988) Measurement of intracellular $\mathrm{Ca}^{2+}$ in cerebellar Purkinje neurons in culture: resting distribution and response to glutamate. Brain Res Bull 21:353-361.

Connor JA, Kretz R, Shapiro E (1986) Calcium levels measured in a presynaptic neuron of Aplysia under conditions that modulate transmitter release. J Physiol (Lond) 375:625-642.

Dale N, Kandel ER (1990) Facilitatory and inhibitory transmitters modulate spontaneous transmitter release at cultured Aplysia sensorimotor synapses. J Physiol (Lond) 421:203-222.

Delaney KR, Zucker RS, Tank DW (1989) Calcium in motor nerve terminals associated with posttetanic potentiation. J Neurosci 9:35583567.

Del Castillo J, Katz B (1954) Statistical factors involved in neuromuscular facilitation and depression. J Physiol (Lond) 124:574-585.

Edmonds B, Klein M, Dale N, Kandel ER (1990) Contributions of two types of calcium channels to synaptic transmission and plasticity. Science 250:1142-1147.

Eliot LS, Dudai Y, Kandel ER, Abrams TW (1989) $\mathrm{Ca}^{2+} /$ calmodulin sensitivity may be common to all forms of neural adenylate cyclase. Proc Natl Acad Sci USA 86:9564-9568.

Eliot LS, Hawkins RD, Kandel ER, Schacher S (1994) Pairing-specific, activity-dependent presynaptic facilitation of Aplysia sensory-motor neuron synapses in isolated cell culture. J Neurosci 14:368-383.

Eusebi F, Molinaro M, Caratsch CG (1986) Effects of phorbol ester on spontaneous transmitter release at frog neuromuscular junction. Pfluegers Arch 406:181-183.

Gage PW, Hubbard JI (1966) An investigation of the post-tetanic potentiation of end-plate potentials at a mammalian neuromuscular junction. J Physiol (Lond) 184:353-375.

Ghirardi M, Braha O, Hochner B, Montarolo PG, Kandel ER, Dale N (1992) Roles of PKA and PKC in facilitation of evoked and spontaneous transmitter release at depressed and nondepressed synapses in Aplysia sensory neurons. Neuron 9:479-489.

Gingrich KJ, Byrne JH (1985) Simulation of synaptic depression, posttetanic potentiation, and presynaptic facilitation of synaptic potentials from sensory neurons mediating gill-withdrawal reflex in Aplysia. J Neurophysiol 53:652-669.

Griffith WH (1990) Voltage-clamp analysis of posttetanic potentiation of the mossy fiber to CA3 synapse in hippocampus. J Neurophysiol 63:491-501.

Hawkins RD, Abrams TW, Carew TJ, Kandel ER (1983) A cellular mechanism of classical conditioning in Aplysia: activity-dependent amplification of presynaptic facilitation. Science 219:400-404.

Hidaka H, Inagaki M, Kawamoto S, Sasaki Y (1984) Isoquinolinesulfonamides, novel and potent inhibitors of cyclic nucleotide dependent protein kinase and protein kinase C. Biochemistry 23:50365041 .

Hirsh JK, Silinsky EM, Solsona CS (1990) The role of cyclic AMP and its protein kinase in mediating acetylcholine release and the action of adenosine at frog motor nerve endings. Br J Pharmacol 101:311318. 
Hirst GDS, Redman SJ, Wong K (1981) Post-tetanic potentiation and facilitation of synaptic potentials evoked in cat spinal motoneurones. J Physiol (Lond) 321:97-109.

Jia M, Nelson PG (1986) Calcium currents and transmitter output in cultured spinal cord and dorsal root ganglion neurons. J Neurophysiol $56: 1257-1267$.

Kandel ER (1976) Cellular basis of behavior. San Francisco: Freeman

Klein M, Shapiro E, Kandel ER (1980) Synaptic plasticity and the modulation of the $\mathrm{Ca}^{2+}$ current. J Exp Biol 89:117-157.

Koester J, Kandel ER (1977) Further identification of neurons in the abdominal ganglion of Aplysia using behavioral criteria. Brain Res 121:1-20.

Kretz R, Shapiro E, Kandel ER (1982) Post-tetanic potentiation at an identified synapse in Aplysia is correlated with a $\mathrm{Ca}^{2+}$-activated $\mathrm{K}^{+}$ current in the presynaptic neuron: evidence for $\mathrm{Ca}^{2+}$ accumulation. Proc Natl Acad Sci USA 79:5430-5434.

Kusano K, Landau EM (1975) Depression and recovery of transmission at the squid giant synapse. J Physiol (Lond) 245:13-32.

Leidenheimer NJ, Browning MD, Dunwiddie TV, Hahner LD, Harris RA (1990) Phosphorylation-independent effects of second messenger system modulators on $\gamma$-aminobutyric acid $_{\mathrm{A}}$ receptor complex function. Mol Pharmacol 38:823-828.

Lev-Tov A, Rahamimoff R (1980) A study of tetanic and post-tetanic potentiation of miniature end-plate potentials at the frog neuromuscular junction. J Physiol (Lond) 309:247-273.

Liley AW (1956) An investigation of spontancous activity at the neuromuscular junction of the rat. J Physiol (Lond) 132:650-666.

Lin J-W, Sugimori M, Llinas RR, McGuinness TL, Greengard P (1990) Effects of synapsin I and calcium/calmodulin-dependent protein kinase II on 'spontaneous neurotransmitter release in the squid giant synapse. Proc Natl Acad Sci USA 87:8257-8261.

Llinas R, McGuinness TL, Leonard CS, Sugimori M, Greengard P (1985) Intraterminal injection of synapsin I or calcium/calmodulindependent protein kinase II alters neurotransmitter release at the squid giant synapse. Proc Natl Acad Sci USA 82:3035-3039.

Magleby KL, Zengel JE (1975) A quantitative description of tetanic and post-tetanic potentiation of transmitter release at the frog neuromuscular junction. J Physiol (Lond) 245:183-208.

Malenka RC, Madison DV, Nicoll RA (1986) Potentiation of synaptic transmission in the hippocampus by phorbol esters. Nature 321:175177.

Malinow R, Schulman H, Tsien RW (1989) Inhibition of postsynaptic PKC or CaMKII blocks induction but not expression of LTP. Science 245:862-866.

Miledi R, Parker I (1981) Calcium transients recorded with arsenazo III in the presynaptic terminal of the squid giant synapse. Proc R Soc Lond [Biol] 212:197-211.

Miledi R, Thies R (1971) Tetanic and post-tetanic rise in frequency of miniature end-plate potentials in low-calcium solutions. J Physiol (Lond) 212:245-257.

Muller D. Turnbull J, Baudry M, Lynch G (1988) Phorbol esterinduced synaptic facilitation is different than long-term potentiation. Proc Natl Acad Sci USA 85:6997-7000.

Pieroni JP, Byrne JH (1992) Differential effects of serotonin, FMRFamide, and small cardioactive peptide on multiple, distributed processes modulating sensorimotor synaptic transmission in Aplysia. J Neurosci 12:2633-2647.

Rayport SG, Schacher S (1986) Synaptic plasticity in vitro: cell culture of identified Aplysia neurons mediating short-term habituation and sensitization. J Neurosci 6:759-763.

Regehr WG, Tank DW (1991) The maintenance of LTP at hippocampal mossy fiber synapses is independent of sustained presynaptic calcium. Neuron 7:451-459.

Reuhl TOK, Amador M, Moorman JR, Pinkham J, Dani JA (1992) Nicotinic acetylcholine receptors are directly affected by agents used to study protein phosphorylation. J Neurophysiol 68:407-416.
Reymann KG, Frey U, Jork R, Matthies H (1988a) Polymyxin B, an inhibitor of protein kinase $C$, prevents the maintenance of synaptic long-term potentiation in hippocampal CAl neurons. Brain Res 440: 305-314.

Reymann KG, Brodemann R, Kase H, Matthies H (1988b) Inhibitors of calmodulin and protein kinase $\mathrm{C}$ block different phases of hippocampal long-term potentiation. Brain Res 461:388-392.

Roberts WM, Jacobs RA, Hudspeth AJ (1990) Colocalization of ion channels involved in frequency selectivity and synaptic transmission at presynaptic active zones of hair cells. J Neurosci 10:3664-3684.

Rosenthal J (1969) Post-tetanic potentiation at the neuromuscular junction of the frog. J Physiol (Lond) 203:121-133.

Sacktor TC, Schwartz JH (1990) Sensitizing stimuli cause translocation of protein kinase $\mathrm{C}$ in Aplysia sensory neurons. Proc Natl Acad Sci USA 87:2036-2039.

Schacher S, Montarolo PG, Kandel ER (1990) Selective short- and long-term effects of serotonin, small cardioactive peptide, and tetanic stimulation on sensorimotor synapses of Aplysia in culture. J Neurosci 10:3286-3294.

Shapira R, Silberberg SD, Ginsburg S, Rahamimoff R (1987) Activation of protein kinase $\mathrm{C}$ augments evoked transmitter release. $\mathrm{Na}$ ture 325:58-60.

Sossin WS, Schwartz JH (1992) Selective activation of $\mathrm{Ca}^{2+}$-activated PKCs in Aplysia neurons by 5-HT. J Neurosci 12:1160-1168.

Sugita S, Goldsmith JR, Baxter DA, Byrne JH (1992) Involvement of protein kinase $\mathrm{C}$ in serotonin-induced spike broadening and synaptic facilitation in sensorimotor connections of Aplysia. J Neurophysiol 68:643-651.

Swandulla D, Hans M, Zipser K, Augustine GJ (1991) Role of residual calcium in synaptic depression and posttetanic potentiation: fast and slow calcium signaling in nerve terminals. Neuron 7:915-926.

Takeuchi A, Takeuchi N (1962) Electrical changes in the pre- and post-synaptic axons of the giant synapse of Loligo. J Gen Physiol 45: $1181-1193$

Thies RE (1965) Neuromuscular depression and the apparent depletion of transmitter in mammalian muscle. J Neurophysiol 28:427442

Walters ET (1987) Multiple sensory neuron correlates of site-specific sensitization in Aplysia. J Neurosci 7:408-417.

Walters ET, Byrne JH (1983) Associative conditioning of single sensory neurons suggests a cellular mechanism for learning. Science 219 : 405-408.

Walters ET, Byrne JH (1984) Post-tetanic potentiation in Aplysia sensory neurons. Brain Res 293:377-380.

Walters ET, Byrne JH (1985) Long-term enhancement produced by activity-dependent modulation of Aplysia sensory neurons. J Neurosci 5:662-672.

Weinreich D (1971) Ionic mechanism of post-tetanic potentiation at the neuromuscular junction of the frog. J Physiol (Lond) 212:431446.

Yamamoto C, Higashima M, Sawada S (1987) Quantal analysis of potentiating action of phorbol ester on synaptic transmission in the hippocampus. Neurosci Res 5:28-38.

Zengel JE, Magleby KL (1981) Changes in miniature endplate potential frequency during repetitive nerve stimulation in the presence of $\mathrm{Ca}^{2+}$, $\mathrm{Ba}^{2+}$, and $\mathrm{Sr}^{2+}$ at the frog neuromuscular junction. J Gen Physiol 77: 503-529.

Zucker RS (1989) Short-term synaptic plasticity. Annu Rev Neurosci 12:13-31.

Zucker RS, Bruner J (1977) Long-lasting depression and the depletion hypothesis at crayfish neuromuscular junctions. J Comp Physiol 121 : 223-240.

Zucker RS, Lara-Estrella LO (1983) Post-tetanic decay of evoked and spontaneous transmitter release and a residual-calcium model of synaptic facilitation at crayfish neuromuscular junctions. J Gen Physiol $81: 355-372$. 